\title{
Mapping reciprocal effects and interactions with plant density stress in Zea mays L.
}

\author{
M Gonzalo ${ }^{1,2}$, TJ Vyn², JB Holland ${ }^{3}$ and LM McIntyre ${ }^{2,4}$ \\ ${ }^{1}$ Nidera SA, Buenos Aires, Argentina; ${ }^{2}$ Department of Agronomy, Purdue University, West Lafayette, IN, USA; ${ }^{3} U S D A-A R S$, Plant \\ Science Research Unit, Department of Crop Science, North Carolina State University, Raleigh, NC, USA and ${ }^{4}$ Department of Molecular \\ Genetics and Microbiology, University of Florida, Gainesville, FL, USA
}

\begin{abstract}
Reciprocal effects are due to genetic effects of the parents (i.e. maternal and paternal effects), cytoplasmic effects and parent-of-origin effects. However, in Zea mays L. the extent to which reciprocal effects exist, or can be attributed to specific underlying components, remains an area of interest and study. Reciprocal effects have been reported by several investigators for various agronomic characters in different types of maize materials for grain and silage usage. Maize geneticists and breeders have recognized reciprocal effects as one source of genetic variability, but the lack of consistency in the observation of these effects, particularly due to stress conditions, has prevented a systematic exploitation of these effects in practical breeding programs. There is mounting molecular evidence for underlying mechanisms in maize, which could be responsible for both the existence, and the instability of reciprocal effects. In this
\end{abstract}

study, we developed population of reciprocal backcrosses based on an initial set of recombinant inbred lines. This population was used for dissecting reciprocal effects into the underlying components (maternal, cytoplasmic and parentof-origin) effects. We also developed statistical framework to identify and map contributions of specific nuclear chromosomal regions to reciprocal effects. We showed that differences in maternal parents, endosperm DNA and maternally transmitted factors collectively influence reciprocal effects early during the season, and that their influence diluted at later stages. We also found evidence that parent-of-origin effects in the sporophyte DNA existed at all stages and played an important role in establishing differences between reciprocal backcrosses at later developmental stages.

Heredity (2007) 99, 14-30; doi:10.1038/sj.hdy.6800955; published online 2 May 2007

Keywords: maternal effects; epigenetics; stress response; parent-of-origin effects

\section{Introduction}

Maize geneticists and breeders have recognized reciprocal effects as one source of genetic variability (Mann and Pollmer, 1981; Seitz et al., 1995). Reciprocal effects may account for a large portion of the genetic variance in certain forms of resistance to insect feeding (Dhliwayo et al., 2005). However, there is little consensus in the literature concerning the relative importance and systematic exploitation of these effects in practical breeding programs. This is because reciprocal differences were generally not consistent across environments and did not have a uniform sign for all hybrids tested between two germplasm groups (Mann et al., 1981; Melchinger et al., 1985). However, the presence of reciprocal differences in the evaluation of breeding materials has been documented since the early days of modern breeding (Pollmer et al., 1979). These results were puzzling at the time of these studies, and not clearly interpretable in part because of limited understanding of epigenetics. Current

Correspondence: Dr LM McIntyre, Department of Molecular Genetics and Microbiology, College of Medicine, University of Florida, Gainesville, FL 32610-0266, USA.

E-mail: mcintyre@ufl.edu

Received 12 April 2006; revised 28 September 2006; accepted 2 February 2007; published online 2 May 2007 molecular studies may provide some insight into how reciprocal effects are modified by environmental triggers. For example, if imprinting is the cause of some reciprocal difference among lines, a later-season stress may induce changes in methylation on the imprinted regions, resulting in phenotypic changes.

Epigenetic phenomena occur in several organisms and in different kingdoms, suggesting that this variation is fundamental to the regulation of gene expression (for a review see Finnegan, 2001). Known molecular mechanisms for epigenetic phenomena include DNA methylation, histone modification, chromatin remodeling and RNA interference (Cervera et al., 2002; Rutherford and Henikoff, 2003). Together these phenomena are being studied as the 'epigenome'.

DNA methylation is one form of epigenetic control, and it is associated with gene silencing and transposon control in fungi and plants (for a review see Martienssen and Colot, 2001). DNA methylation in maize changes depending upon the tissue and the developmental stage (Tsaftaris et al., 1999). External (environmental) signals also affect the extent of DNA methylation (Sherman and Talbert, 2002; Steward et al., 2002). Stressful conditions have been shown to result in more methylated (less expressed) DNA. Methylation levels differ among genotypes and might contribute to loss of fitness observed upon inbreeding (Kakutani et al., 1996). Vigorous hybrids 
have been shown to be resistant to stress-induced methylation and suppression of genome activity in their DNA (Tsaftaris and Polidoros, 2000; Tani et al., 2005).

DNA methylation may also occur as a result of imprinting (reviewed by Autran et al., 2005). Imprinting, the differential expression of a gene depending on the parent of origin, is commonly assumed to be the result of DNA methylation. The regulatory mechanism of imprinted gene expression implies that a cell can discriminate between alleles and determine, based upon the parent which transmitted that allele, which one is to be transcribed. It is presumed that parental alleles are differentially marked by an epigenetic imprint, which can modulate gene activity without imposing an irreversible change on the nucleotide sequence. Kermicle (1970) first described single-gene imprinting for alleles of the maize $r 1$ locus that showed parent-specific differences in gene expression during endosperm development. Extensive imprinting during endosperm and early embryo development has been reported in maize (Evans and Kermicle, 2001; Danilevskaya et al., 2003; GutierrezMarcos et al., 2004; Lauria et al., 2004; Grimanelli et al., 2005). The effect of imprinting in maize is often on the maternally transmitted allele, which undergoes demethylation in the endosperm relative to the paternally transmitted allele which remains methylated (Alleman and Doctor, 2000; Lauria et al., 2004). This is in contrast to mammalian systems, which often add methyl groups to silence genes during imprinting (for a review on imprinting in mammals see Reik and Walter, 2001).

Epigenetic phenomena would be expected to manifest themselves as differences between reciprocal crosses. In a reciprocal cross, the same two parents are used, but their maternal and paternal roles are reversed. Differences between reciprocal crosses have been reported by several investigators for various agronomic characters in different types of maize materials for grain (Mann and Pollmer, 1981; Mann et al., 1981; Melchinger et al., 1985) and silage usage (Seitz et al., 1995). Perhaps the most compelling evidence for reciprocal differences was obtained by Schnell and Singh (1978) working with three-way crosses, who observed sizeable reciprocal differences to the advantage of hybrids produced on the single-cross seed parents as compared with their reciprocal forms produced on the parent inbred. If reciprocal differences have a heritable genetic component, these differences should be amenable to modeling and mapping in an appropriate population.

Several genetic factors may contribute to differences between reciprocal crosses. Maize kernels are composed of three genetically distinct tissues: the pericarp (maternal tissue that comprises only the outermost cell layers of the seed), the endosperm, and the embryo (also known as the sporophyte). The endosperm is a triploid tissue composed of two sets of chromosomes received from the seed parent and one set from the pollen parent. Endosperm tissues play an important role during the sporophyte emergence and first stages of growth. The embryo is a diploid tissue. DNA in the embryo can be divided into nuclear and cytoplasmic (extranuclear) DNA. Differences between reciprocal crosses can be partitioned into differences because of maternal nuclear genotypes, differences in endosperm DNA, differences in the sporophyte cytoplasmic DNA and differences in the structure of the sporophyte nuclear DNA. Differences due to DNA in the endosperm can be caused by epigenetic effects (i.e. action of imprinted genes), but they can also result from many other factors (e.g. the activity of dosage-sensitive genes in the endosperm, from maternally transmitted transcription factors/proteins, or from the activity of products that are encoded by the genome of the maternally inherited organelles in the endosperm). In this paper, we refer to the maternal nuclear DNA, endosperm DNA, and all maternally transmitted factors collectively as the contribution of the seed parent.

Assuming that the seed and pollen parents share a common environment, differences between reciprocals are the sum of the effect of the seed parent, the effect of the pollen parent, the cytoplasmic effect and the interaction between the seed/pollen parent's genetic effect with the nuclear component of the progeny (Figure 1). We refer to this last component as the effect of the 'parent-of-origin' effect on the sporophyte. Since maize kernels are matroclinous, the progeny kernels of crosses between diverse inbred lines are structurally (shape and size) like the seed parent, maternal factors and parent-of-origin effects in the endosperm should be phenotypically evident in kernel characteristics and early developmental stages (Eagles and Hardacre, 1979).

We undertook this study to examine the influence of reciprocal effects on the phenotype of the progeny sporophyte and to study the impact of stress upon these effects. We developed methodology for mapping reciprocal effects and tested this approach in maize. We evaluated phenotypic responses ranging from kernel traits to flowering for a total of 92 reciprocal crosses derived from backcrosses of 23 recombinant inbred lines (RILs) to the two parental lines. The effect of stress on reciprocal effects was examined by growing each of the genotypes at two population densities that produced contrasting levels of inter-plant competition. Our results suggest that the maternal effect, alone or in combination with 'parent-oforigin' effects, is involved in phenotypic characteristics in the sporophyte. For flowering traits, there is indirect evidence for 'parent-of-origin' effects as the sole mechanism responsible for reciprocal differences in some genomic regions. Interestingly, cytoplasmic effects were minimal in this study. By examining responses under two different population densities, we determined that the maternal effect, 'parent-of-origin' and cytoplasmic effects changed over time and in response to plant population density.

\section{Methods}

\section{Maize population}

A population of 204 RILs derived from the cross B73 $\times$ Mo17 was originally developed by Charles Stuber and Lynn Senior at North Carolina State University. The RIL population was previously genotyped with 233 restriction fragments length polymorphism, simple sequence repeat and isozyme markers by Senior et al. (1996). Genotype data for these RILs are available at www.MaizeGDB.org (the most updated map is labeled 'Map B73.Mo17 RI 1999') and directly by downloading the following file (http://www4. ncsu.edu/jholland/MOBRIDB.xls). Seeds of these RILs are available upon request to JB Holland.

Twenty-three RILs were selected from the population. These lines were selected based upon their marker type for a four-locus quantitative trait loci (QTL) model for 


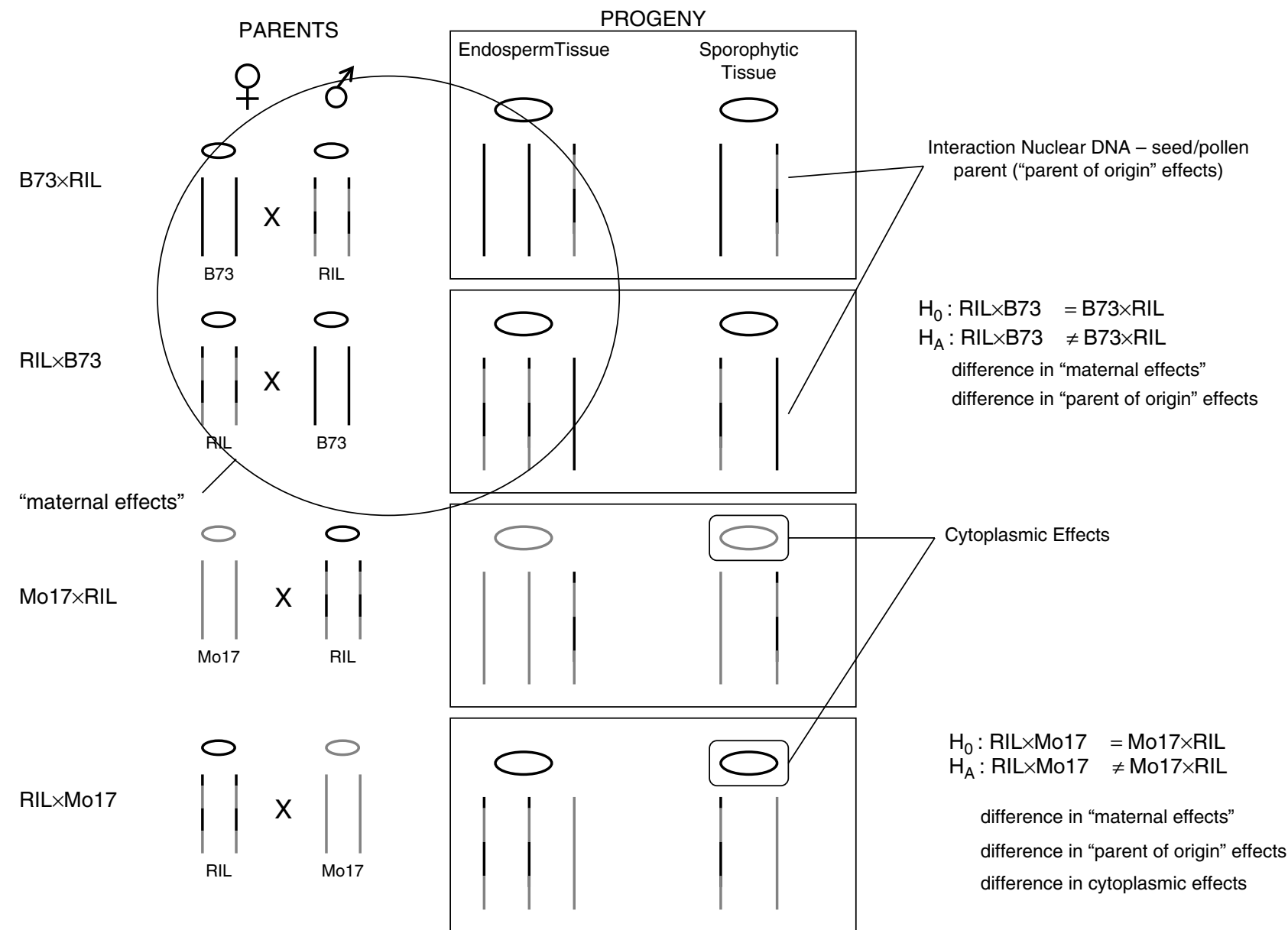

Figure 1 Schematic representation of the differences between reciprocal crosses. One chromosome is represented to show the possible sources for differences between reciprocal crosses. Black segments represent B73 alleles, gray segments represent Mo17 alleles. If RIL $\times$ B73 is different from B73 $\times$ RIL, it may be attributed to differences in the endosperm, the seed and pollen parents (collectively 'maternal effect'), or a 'parent-of-origin' type effect in the nuclear DNA. If RIL $\times$ Mo17 is different from Mo17 $\times$ RIL, differences in cytoplasmic DNA may also contribute.

barrenness mapped using the entire population in 2003. Nine of the lines had the unfavorable alleles at all four loci, while the other 12 lines had the favorable alleles at all four loci. These contrasting sets were used to obtain a cleaner validation for the effect of the QTL for barrenness. However, it is important to notice that no information on the reciprocal difference for any trait was available when the lines were selected; therefore, lines can be regarded as randomly chosen for differences between reciprocals. Each line was backcrossed to both parental lines; all backcrosses were made in both directions, using each line as a female and as a male. Entries in this study were the four backcrosses (RIL $\times$ Mo17, Mo17 $\times$ RIL, RIL $\times$ B73, B73 $\times$ RIL) for each of the 23 RILs, making a total of 92 entries. Mo17 $\times$ B73 and B73 $\times$ Mo17 hybrids were included as check entries. All seed was made in the same nursery field in the summer of 2004 at the Purdue University Agricultural Research Center in West Lafayette, Indiana.

\section{Genetic model for the differences between reciprocal} crosses

Depending upon the specific genetic material available, reciprocal effects can be further partitioned into indirect effects of maternal and paternal genes, cytoplasmic effects, direct effects of nuclear genes and interactions between these factors. A detailed genetic model of the underlying components that contribute to reciprocal effects has been developed. We apply that model to the specific set of genetic material in this study. Further, the model is developed for a set of RILs, and so marker information is incorporated. This model then allows mapping of the reciprocal effects onto particular chromosomal regions. Details are given in Appendix A.

\section{Experimental design and data collection}

The kernel weight for five independent samples of 100 kernels for each of the 92 entries in the study was determined before planting the experiments. It is important to notice that the kernels weighed correspond to the same generation as the backcross progeny. Seed size, for example, is a trait for which a large maternal effect has been demonstrated, and which has important ecological consequences (Roach and Wulff, 1987). Studies have shown an effect of seed size on germination characteristics, and on seedling size (reviewed by Aksel, 1977). A large maternal effect on seed size, embryo oil and protein, and zein synthesis has been found in maize 
(Eagles and Hardacre, 1979; Bagnara and Daynard, 1983; Chaudhuri and Messing, 1994). In addition to influencing the rate or timing of germination, maternal effects can also influence the sensitivity of seeds to environmental conditions. For example, in sensitivity to cold during germination (Cal and Obendorf, 1972) and tolerance to drying injury (Bdliya and Burris, 1988) maternal effects were found to be important. Thus, we used the kernel weight as a proxy for maternal effect.

Entries were arranged in a split-split-split-plot design with two replicates in each of three locations. The wholeplot treatment factor was density with two levels, high density (100000 seeds ha ${ }^{-1}$ (38 seeds row $\left.{ }^{-1}\right)$ ) and low density (50000 seeds ha ${ }^{-1} \quad\left(19\right.$ seeds row $\left.\left.{ }^{-1}\right)\right)$. The sub-plot treatment factor was the RIL genotype with 25 levels (the 23 RILs and two control lines). The sub-subplot treatment factor was backcross parent with two levels (B73 and Mo17). Control lines were assigned so that the check hybrid B73 $\times$ Mo17 was planted in one of the 25 sub-sub-plots. This was attained by including line Mo17 as one of the 25 levels in sub-sub-plots where B73 was the backcross parent, and including line B73 as one of the 25 levels in sub-sub-plots where Mo17 was the backcross parent. In order to account for soil variability, genotypes within a density by parent combination were randomized according to a 5 by 5 lattice design. To assure uniform pollen availability, pollinator rows of different maturity were uniformly distributed across the study.

Each sub-sub-plot consisted of four rows measuring $5 \mathrm{~m}$ long with $0.76-\mathrm{m}$ inter-row spacing and a $1-\mathrm{m}$ alley at the end of each plot. The two border rows were planted with a short-statured, early maturity commercial hybrid (Battleground 3336), and the two center rows were planted with the backcrosses. One of these two center rows was planted with an RIL $\times$ parent backcross, and the other was planted with the parent $\times$ RIL reciprocal backcross.

The experiment was planted on the 4th of May in 2005 at the Purdue University Agronomy Center for Research and Education near West Lafayette (40 33' $36^{\prime \prime}$ N, $8655^{\prime}$ $\left.48^{\prime \prime} \mathrm{W}\right)$, Indiana on a soil classified as poorly drained Chalmers silty clay loam, on the 5th of May in 2005 at our second location in the Purdue University Agronomy Center for Research and Education near West Lafayette $\left(4033^{\prime} 36^{\prime \prime} \mathrm{N}, 8655^{\prime} 48^{\prime \prime} \mathrm{W}\right)$, Indiana on a soil classified as Drummer silty clay loam, and on the 11th of May in 2005 in the Throckmorton-Purdue Agricultural Center (TPAC) (40 $17^{\prime} 52^{\prime \prime} \mathrm{N}, 8654^{\prime} 10^{\prime \prime} \mathrm{W}$ ) near Romney, Indiana on a Raub silt loam soil.

Measurements were taken on the central two rows of each sub-sub-plot. In order to account for the reduced interplant competition near the ends of the plots, data were not collected on the first and last 3 plants in a row. Height measurements were recorded on five consecutive plants per row, and the first plant was arbitrarily selected from among the second set of five plants for the first measurement. Subsequent measurements were scored on the same individuals. Data collected included heights to the uppermost stretched leaf tip at the stages of 7 (V7) and 12 (V12) developed leaves and height to the collar of the uppermost leaf 2 weeks after silking. The V7 and V12 stages corresponded to plants approximately 4 and 7 weeks old and 1 and $1.5 \mathrm{~m}$ tall, respectively. In addition, the date of first visible anther, and date of first visible stigma were tracked on all plants. A row was assigned a median anthesis date when $50 \%$ of the individuals in that row had visible anthers. Similarly, median silking date was recorded as the date when $50 \%$ of the plants showed visible stigma. Days to anthesis and silking were obtained by subtracting the Julian date of planting from the Julian date of median anthesis and silking.

\section{Statistical analyses}

Standard analysis of variance (ANOVA) models for split-split-split-plot designs were used to analyze height at each time point and time to flowering data. Time to flowering data are often strongly skewed (Vermerris and McIntyre, 1999), which can result in violation of the assumption of normality of residuals required in ANOVA models. Since there were no censored data in our study, and log-normal survival models fit well, log-transformed flowering data were analyzed in the ANOVA framework. This approach is equivalent to fitting a log-normal model in survival time analysis with no censored data; with the advantage that model estimates effects are normally distributed (Lawless, 1982). The ANOVA model used to analyze height data was

$$
\begin{aligned}
Y_{i j k l m n o p}= & +L_{i}+D_{j}+(L D)_{i j}+\delta_{i k}+(D \delta)_{i j k}+R_{l} \\
& +(L R)_{i l}+(D R)_{j l}(L D R)_{i j l}+(D \delta R)_{i j k l} \\
& +\gamma_{i j k m}+B_{n}+(L B)_{i n}+(D B)_{j n}+(L D B)_{i j n} \\
& +(R B)_{l n}+(L R B)_{i l n}+(D R B)_{j l n}+(L D R B)_{i j l n} \\
& +(D \delta R B)_{i j k l n}+S_{o}+(L S)_{i o}+(D S)_{j o} \\
& +(L D S)_{i j o}+(R S)_{l o}+(L R O)_{i j o}+(D R O)_{j l o} \\
& +(L D R O)_{i j l o}+(B S)_{n o}+(L B S)_{i n o}+(D B S)_{j n o} \\
& +(L D B S)_{i j n o}+(R B S)_{l n o}+(L R B S)_{i l n o}+(D R B S)_{j l n o} \\
& +(L D R B S)_{i j l n o}+(D \delta R B S)_{i j k l n o}+\varepsilon_{i j k l m n o p}
\end{aligned}
$$

$Y_{i j k l m n o p}$ is the height of the $p$ th plant from the backcross between the RIL $l$ and parent $n$, for reciprocal $o$, planted in the density treatment $j$, block $m$, replicate $k$ and location $i$. $L_{i}, D_{j}, \delta_{i k}, R_{l}, \gamma_{i j k m}, B_{n}$ and $S_{o}$ represent effects of location, density, replicate within location, RIL, block within location by replicate by density, backcross parent and reciprocal, respectively, and $\varepsilon_{i j k l m o p}$ is a random error. Location, replicate within location, block within a location by replicate by density, line and their interactions were considered random effects. Density, backcross parent and reciprocal were considered fixed effects. For the analysis of time to flowering data, the term $(\mathrm{D} \delta \mathrm{RBS})_{i j k l n o}$ is not estimable as only one observation per row was recorded. The five-way interactions were not significant for all five traits; thus, differences between reciprocal crosses were estimated across locations. Density interactions were often significant, and so the model was then fit for each density separately. F-tests for the four-way interaction density by backcross parent by line by reciprocal was used to determine if the average differences between reciprocal crosses for a given RIL and backcross parent combination were affected by density treatment.

Estimates of the differences between reciprocal crosses (see equations 5 and 6 in Appendix A) for each density 
were obtained for each RIL as the difference in least squares means between reciprocals. A $t$-statistic was constructed to test this difference between reciprocal crosses. For each trait, the $92 P$-values (2 densities, 23 RILs, 2 backcross parents) were corrected for multiplicity using the false discovery rate (FDR) procedure (Benjamini and Hochberg, 1995) and reviewed by Verhoeven et al. (2005) at the 5\% level.

\section{Mapping differences between reciprocal crosses}

To estimate the effect of each marker on the difference between reciprocal crosses, we divided the 92 estimated reciprocal differences obtained from the ANOVA model into $\Lambda_{B, M, l}^{m}, \quad \Lambda_{B, B, l}^{m}, \quad \Lambda_{M, M, l}^{m}$ and $\Lambda_{M, B, l}^{m}$ represented by equations 7-10 in Appendix A depending on the marker genotype of the RIL and the backcross parent.

For each marker, an ANOVA model was used to estimate the average effect $v^{m}$ of the marker on the difference between reciprocal crosses. The ANOVA model used was

$$
\Lambda_{i j k}^{m}=\mu+G_{i}+D_{j}+(G D)_{i j}+\varepsilon_{i j k}
$$

where $\Lambda_{i j k}^{m}$ is the $k$ th difference between reciprocal crosses associated with group $i$ in density $j . G_{i}$ is the effect of the genotypic group (i.e. $\mathrm{M}, \mathrm{M}, 1$ as above), $D_{j}$ represents the density effect and $\varepsilon_{i j k}$ represents a random error term. Density, group and the interaction density by group were included in the model as fixed effects.

For each density, an estimate of $v_{j}^{m}$ that represents equation 17 in the appendix was obtained from the ANOVA model

$$
v_{j}^{m}=\frac{\left(\mu_{3 j}-\mu_{1 j}\right)-\left(\mu_{2 j}-\mu_{4 j}\right)}{2},
$$

where $v_{j}^{m}$ is the estimated average effect of the marker $m$ on the difference between reciprocal crosses in density $j$, and $\mu_{i j}$ represents the least squares mean of group $i$ in density $j$. The significance of $v_{j}^{m}$ was determined by constructing $t$ statistics to test

$$
H_{0}: v_{j}^{m}=0 \text {. }
$$

There were 233 markers tested. A marker was declared significantly associated with the difference between reciprocal crosses in density $j$ if the nominal $P$-value from this test was less than 0.01 .

For kernel weight, the estimates of the difference between reciprocal crosses (equations 5 and 6 were obtained from the differences in mean kernel weight of the five samples of 100 kernels. The same grouping criteria were used for kernel weight, but the ANOVA model did not include a density and a density by group term. Estimation and testing of $v^{m}$ were performed as for the other traits.

All analyses were conducted in SAS (SAS Institute, Cary, NC, USA). The data and SAS programs are available on request.

\section{Results and discussion}

Significant differences between reciprocals were found for all traits evaluated in this study (Tables 1 and 2). Overall, cytoplasmic effects were not strong and reciprocal differences were consistent with the hypothesis that maternal effects were associated with differences between reciprocals at the V7, V12 stages, anthesis and
Table 1 Number of significant differences for the density by reciprocal interaction and for each density

\begin{tabular}{lccccc}
\hline Density & $\begin{array}{c}\text { Plant height } \\
\text { V7 stage }\end{array}$ & $\begin{array}{c}\text { Plant height } \\
\text { V12 stage }\end{array}$ & $\begin{array}{c}\text { Final } \\
\text { height }\end{array}$ & $\begin{array}{c}\text { Days to } \\
\text { anthesis }\end{array}$ & $\begin{array}{c}\text { Days to } \\
\text { silking }\end{array}$ \\
\hline Low & 14 & 10 & 2 & 7 & 6 \\
High & 10 & 3 & 2 & 6 & 4 \\
\hline
\end{tabular}

A false discovery rate of $5 \%$ for each trait was used to account for multiple testing.

silking. However, the strength of the relationship and the pattern of variation suggests that maternal effects alone can not explain our observations. We infer that 'parent-of-origin' effects are present in all of the traits we measured in this study.

The impact of density on the differences between reciprocals was pronounced in the V7 and V12 stages and the ANOVA model indicated that the density by cross interaction was significant (Table 1). This is interesting, as it is consistent with an interaction between stress and the factors controlling the differences between reciprocals. In addition, the relationship between differences in reciprocals across traits was often different between the two densities. This also suggests an interplay between mechanisms responsible for stress response and those involved in reciprocal differences. We present all of our findings for the two densities separately to clearly demonstrate the differential response between densities.

Phenotypic differences between reciprocal crosses

Maternal effects: Reciprocal differences for kernel weight were significant for all 23 RILs in at least one of the two backcrosses (Table 2). Sixteen of the 23 RILs show reciprocal differences for both backcrosses, four show significant reciprocal differences only for the Mo17 backcross, and three were significant only in the B73 backcross. Differences between the kernel weights of the reciprocal, with the RIL as the seed parent and RIL as the pollen parent ranged from -14.4 to $12.7 \mathrm{~g} 100$ kernels $^{-1}$. The RIL made heavier kernels $50 \%$ of the time in backcrosses with B73 (interquartile range from 4.1 to -5.7 and the empirical 5 and $95 \%$ range was from 6.41 to -10.3 ) and $30 \%$ of the time in crosses with Mo17 (interquartile range from 0.04 to $-10.2 ; 5$ and $95 \%$ range was from 2.91 to -14.3$)$.

Reciprocal differences were also common for plant height at the V7 stage. Out of 46 comparisons between reciprocal means, 22 and $30 \%$ were significant in highand low-density stands, respectively (Table 1). In order to determine whether differences in plant height at the V7 and V12 stages were explained by the initial differences in kernel weight, we regressed the difference in kernel weight onto the difference in plant height for each density. Reciprocal differences at the V7 stage were associated with differences in kernel weight in both densities. The proportion of variation in the V7 stage explained by kernel weight in high density is 0.53 and for low density is 0.43 (Figure 2a). The proportion of variation explained by kernel weight is markedly lower in the V12 stage ( 0.36 for high density and 0.28 for low density; Figure 2b). Since the relationship reflects a positive correlation, one explanation is that maternal 
Table 2 Differences between reciprocals

\begin{tabular}{|c|c|c|c|c|c|c|c|c|c|c|c|c|}
\hline \multirow[t]{2}{*}{ RIL } & \multirow{2}{*}{$\begin{array}{l}\text { Backcross } \\
\text { parent }\end{array}$} & \multicolumn{5}{|c|}{ Low density } & \multicolumn{5}{|c|}{ High density } & \multirow{2}{*}{$\begin{array}{l}\text { Kernel weight } \\
\left(\mathrm{g} 100 k^{-1}\right)\end{array}$} \\
\hline & & $\begin{array}{l}\text { V7 height } \\
(\mathrm{cm})\end{array}$ & $\begin{array}{l}\text { V12 height } \\
(\mathrm{cm})\end{array}$ & $\begin{array}{l}\text { Final } \\
\text { height } \\
\text { (cm) }\end{array}$ & $\begin{array}{c}\text { Days to } \\
\text { anthesis } \\
\text { (days) }\end{array}$ & $\begin{array}{l}\text { Days to } \\
\text { silking } \\
\text { (days) }\end{array}$ & $\begin{array}{l}\text { V7 height } \\
(\mathrm{cm})\end{array}$ & $\begin{array}{l}\text { V12 height } \\
(\mathrm{cm})\end{array}$ & $\begin{array}{l}\text { Final } \\
\text { height } \\
\text { (cm) }\end{array}$ & $\begin{array}{c}\text { Days to } \\
\text { anthesis } \\
\text { (days) }\end{array}$ & $\begin{array}{l}\text { Days to } \\
\text { silking } \\
\text { (days) }\end{array}$ & \\
\hline 5 & B73 & -2.90 & -7.47 & -1.83 & 1.81 & $0.91^{\mathrm{a}}$ & -2.53 & -7.23 & 3.13 & 1.81 & 0.91 & 1.06 \\
\hline $5^{\mathrm{a}}$ & Mol7 & -10.12 & -13.45 & -11.72 & 3.00 & 3.30 & 0.34 & -4.86 & -4.10 & 1.10 & 1.90 & -9.12 \\
\hline 7 & B73 & 2.13 & 0.60 & 2.50 & -0.31 & 0.00 & 1.11 & 9.57 & 3.97 & -0.31 & -0.45 & 4.68 \\
\hline 7 & Mol7 & -1.33 & -1.23 & 2.94 & 0.01 & 0.62 & -0.93 & 4.47 & -4.30 & 0.17 & 0.32 & 0.87 \\
\hline 22 & B73 & -7.73 & -8.03 & -1.17 & 1.51 & 1.91 & -6.68 & -5.93 & 0.63 & 0.98 & 1.39 & -6.19 \\
\hline $22^{\mathrm{a}}$ & Mol7 & 3.94 & 0.32 & $-6.7 \mathrm{I}$ & -1.30 & -0.70 & -3.62 & -3.96 & -2.02 & 0.70 & 1.10 & -12.12 \\
\hline 43 & B73 & -0.80 & 5.30 & -0.03 & -0.16 & -0.01 & 2.00 & 4.70 & 5.35 & -0.16 & -0.29 & 12.69 \\
\hline 43 & Mol7 & -4.43 & -8.27 & -5.35 & 1.13 & 1.11 & -3.73 & -0.27 & -4.57 & 0.16 & 0.14 & 8.70 \\
\hline 50 & B73 & -3.57 & 0.57 & 1.15 & 0.32 & 0.47 & 1.43 & 2.93 & 4.83 & 0.00 & -0.15 & 2.31 \\
\hline 50 & Mol7 & -4.27 & -4.87 & -5.47 & 0.00 & 0.16 & -1.27 & -6.57 & -5.60 & -0.64 & -0.32 & -5.02 \\
\hline 53 & B73 & -2.87 & 1.77 & -4.83 & 0.66 & 0.48 & -0.83 & 7.67 & 2.87 & 0.65 & 0.01 & 0.26 \\
\hline 53 & Mol7 & -6.47 & -4.80 & 2.57 & 0.82 & 0.92 & -5.00 & -11.83 & 4.27 & 1.29 & 1.55 & -12.24 \\
\hline 67 & B73 & 4.37 & 11.30 & -2.65 & -0.49 & -0.47 & 4.27 & 13.30 & 1.93 & -0.79 & -1.36 & 4.08 \\
\hline 67 & Mol7 & -1.40 & 4.67 & 0.56 & -0.65 & -0.78 & -1.87 & 1.33 & -0.27 & -0.48 & -0.62 & 1.75 \\
\hline 105 & B73 & -5.30 & -9.40 & 1.47 & 1.64 & 0.79 & -9.80 & -4.53 & 9.63 & 1.44 & 1.69 & -10.01 \\
\hline 105 & Mol7 & -11.53 & -8.37 & 5.94 & 1.17 & 1.43 & -12.07 & -7.40 & $3.94^{\mathrm{b}}$ & 1.66 & 2.38 & -14.28 \\
\hline 114 & B73 & -6.10 & -2.37 & 1.73 & 0.81 & 0.79 & 0.73 & 4.37 & 0.90 & -0.32 & -0.14 & -2.30 \\
\hline 114 & Mol7 & -8.07 & -12.20 & -5.22 & 1.18 & 2.10 & -5.40 & 4.50 & -0.97 & 0.67 & 0.65 & -7.90 \\
\hline 117 & B73 & -2.30 & -8.37 & -6.95 & 0.64 & 0.78 & -0.23 & 2.60 & 0.03 & 0.79 & -0.14 & 0.87 \\
\hline 117 & Mol7 & -8.90 & -12.53 & -6.19 & 0.98 & 1.56 & -7.73 & -4.43 & -0.70 & 0.98 & 0.93 & -9.28 \\
\hline 138 & B73 & 4.27 & 12.20 & 4.10 & -0.65 & -0.16 & -3.18 & -0.27 & -3.47 & 0.00 & -0.16 & 4.46 \\
\hline 138 & Mol7 & -0.23 & 5.20 & -1.97 & -0.66 & -0.80 & 4.77 & 4.63 & -2.27 & 0.00 & 0.16 & 2.91 \\
\hline 146 & B73 & -1.47 & -3.00 & -5.27 & 0.65 & 0.78 & -4.47 & 1.63 & -3.60 & 0.48 & -0.17 & -0.75 \\
\hline 146 & Mol7 & -10.47 & -11.30 & -7.03 & 0.65 & 1.08 & -1.90 & -2.00 & -2.67 & 0.00 & 0.16 & -7.67 \\
\hline 167 & B73 & -6.73 & -10.87 & -3.93 & 1.49 & 0.79 & -3.23 & -0.60 & -3.57 & 0.66 & 0.48 & -10.29 \\
\hline $167^{\mathrm{b}}$ & Mol7 & 1.47 & 5.74 & 2.46 & -0.01 & -0.64 & -10.88 & -13.84 & -5.12 & 0.98 & 1.07 & -4.44 \\
\hline 168 & B73 & -9.53 & -10.40 & -2.07 & 1.95 & 1.90 & -6.80 & -4.90 & -1.43 & 0.95 & 1.23 & -8.21 \\
\hline 168 & Mol7 & -6.30 & -2.23 & -0.98 & 0.99 & 0.97 & -8.79 & -8.90 & -7.70 & 0.16 & 0.31 & -14.40 \\
\hline 170 & B73 & -0.97 & -3.40 & -0.47 & 0.01 & -0.16 & 0.83 & -1.63 & -0.57 & 0.16 & 0.30 & 4.74 \\
\hline 170 & Mol7 & -2.07 & -4.27 & -3.52 & -0.32 & -0.15 & -4.47 & -13.07 & -10.63 & 0.95 & 1.22 & -5.23 \\
\hline 186 & B73 & -10.10 & -12.10 & -9.70 & 1.17 & 1.31 & -9.40 & -2.47 & -4.13 & 0.00 & 0.80 & -10.67 \\
\hline 186 & Mol7 & -6.53 & -9.40 & -4.46 & 0.50 & 0.95 & -3.93 & -5.60 & -4.13 & -0.33 & 0.00 & -8.25 \\
\hline 193 & B73 & -9.90 & -14.10 & -15.47 & 0.32 & 0.80 & -2.40 & -4.70 & -2.60 & 0.34 & 0.33 & -4.90 \\
\hline 193 & Mol7 & -5.46 & -8.27 & -4.73 & 1.49 & 1.62 & -6.40 & -4.77 & -2.13 & 1.32 & 1.59 & -12.02 \\
\hline 199 & B73 & 1.10 & -4.83 & -4.23 & -0.33 & 0.31 & 3.80 & -1.30 & -5.70 & -0.79 & -0.44 & 3.28 \\
\hline 199 & Mol7 & 2.43 & 6.53 & 1.00 & -0.33 & -0.63 & -2.27 & -3.20 & -1.67 & 0.00 & 0.96 & 0.41 \\
\hline 203 & B73 & -12.90 & -12.50 & -5.33 & 1.15 & 1.90 & -1.83 & -3.70 & -0.07 & 0.16 & 0.62 & -7.60 \\
\hline 203 & Mol7 & -3.67 & 1.43 & 5.10 & 0.98 & 0.63 & -5.66 & -0.03 & -0.47 & 0.94 & 0.92 & -12.82 \\
\hline $252^{\mathrm{a}}$ & B73 & -5.30 & -2.88 & 11.19 & 0.00 & -1.00 & 3.90 & -6.40 & -8.76 & -0.40 & 0.20 & 4.25 \\
\hline 252 & Mol7 & -12.53 & -14.07 & -5.46 & 1.82 & 1.08 & -7.67 & -5.23 & -1.50 & 1.46 & 1.37 & -10.21 \\
\hline $283^{b}$ & B73 & -10.06 & -12.81 & 0.16 & -0.01 & -0.30 & -4.96 & -8.32 & -1.06 & -0.01 & -0.74 & 6.41 \\
\hline 283 & Mol7 & -5.53 & -10.47 & -3.67 & 0.00 & -0.46 & -2.10 & 1.33 & -5.43 & 0.00 & 0.01 & 1.01 \\
\hline 296 & B73 & -0.20 & -0.33 & -6.74 & -0.63 & 0.14 & 6.83 & 9.70 & -5.03 & -0.46 & -0.73 & 1.91 \\
\hline 296 & Mol7 & 4.33 & 6.97 & 1.26 & -0.81 & -0.16 & -5.57 & -4.33 & -7.28 & 0.16 & 0.92 & -3.55 \\
\hline
\end{tabular}

Time to flowering is expressed in days. Differences are presented as the difference between RIL $\times$ parent and parent $\times$ RIL values. Differences that were significant using a false discovery rate of $5 \%$ are in boldface.

andicates that the estimate was obtained from data collected in two out of three locations.

${ }^{\mathrm{b}}$ Data are available for one location only.

effects that are reflected in differences in kernel weight between reciprocals induced differences in seedling vigor, which in turn affected growth such that growth at the V7 stage and, to a lesser degree at the V12 stage, was affected.

The proportion of variation in anthesis at low density explained by kernel weight is 0.35 and at high density is 0.26 , while for silking, the proportion of variation explained at low density was 0.33 and 0.45 at high density (Figure $2 \mathrm{~d}$ and e). The relationship between reciprocal differences in kernel weight and anthesis or silking dates, can potentially be attributed to the maternal effects that affect seedling vigor, and thus indirectly affect the growth and development of the plant, or they may be due to multi-colinearity among effects. That is the correlation between differences in kernel weight and differences at V7, and between differences at V7 and differences in anthesis/silking may result in an observed correlation between kernel weight and anthesis/silking that is not due to shared underlying biological components. We can not determine which of these scenarios is responsible for the observation that differences between reciprocals in anthesis/ silking are associated with differences in kernel weight.

The effect of kernel weight on the differences between reciprocals, and the effects detected in the V7 and V12 stage were not detected for final height (Figure 2c). Note that final height was measured 2 weeks after silking was 

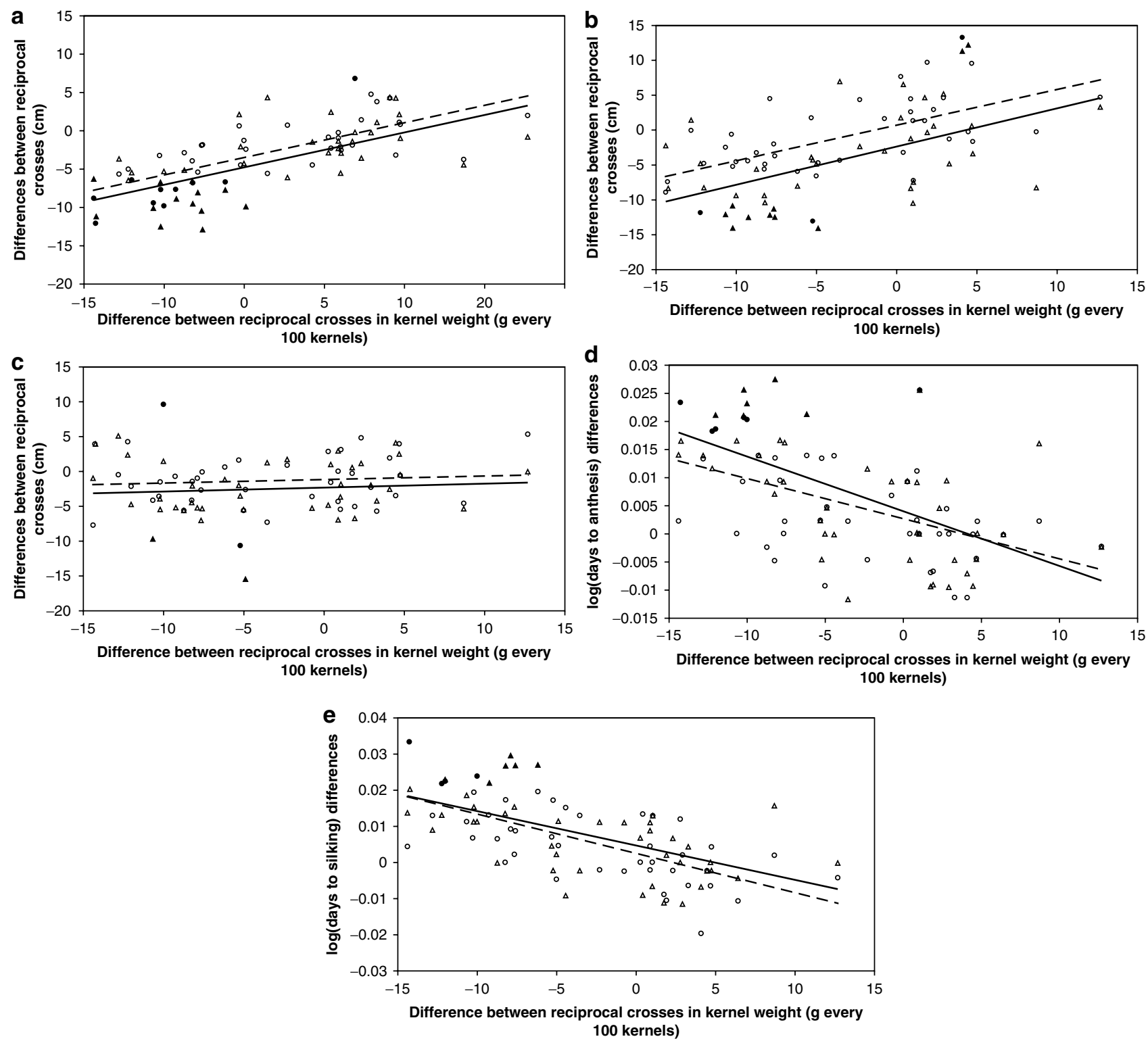

Figure 2 The relationship between differences between reciprocal crosses in kernel weight and differences between reciprocal crosses in (a) height at the V7 stage, (b) height at the V12 stage, (c) final height and days to anthesis (d) and silking (e) (log scale). Significant differences are in black. Circles correspond to differences at high density; triangles correspond to differences at low density. The solid line represents the linear fit for low-density observations and the dashed line represents the linear fit for high-density observations.

completed. Vegetative plant growth in maize stops at flowering (Ritchie et al., 1992) so that differences between reciprocal crosses in plant height that previous to flowering would not be seen in final height if the reciprocal crosses flowered at different times.

'Parent-of-origin' effects: The relationship between kernel weight and V7, V12 stages, flowering and silking indicates that there are possible shared 'maternal effects' for all of these phenotypes. However, the size of the R-squared value indicates that 'maternal effects' alone can not explain the relationship among these reciprocal differences. In addition, kernel weight is not associated with final height. Cytoplasmic effects should be apparent as an increased difference between backcross to the Mo17 parent compared to the B73 parent since the cytoplasm in the RIL is that of the B73 parent and is different from the Mo17 parent. Since there are certainly crosses that have a reciprocal difference in the Mo17 parent and not in the B73 parent, there may well be cytoplasmic effects. However, there are almost the same number of differences in the backcrosses to the B73 parent that are not evident in the backcross to the Mo17 parent (Table 2). In this case, cytoplasmic effects can not be responsible for the difference.

By about the V5 or V6 stages of development (five to six visible leaf collars), the growing point (apical meristem) of the corn plant finishes the task of initiating leaf primordia and completes its developmental responsibilities by initiating the tassel primordium of the plant. At about the same time that the tassel is initiated, the uppermost harvestable (and final) ear is also initiated 

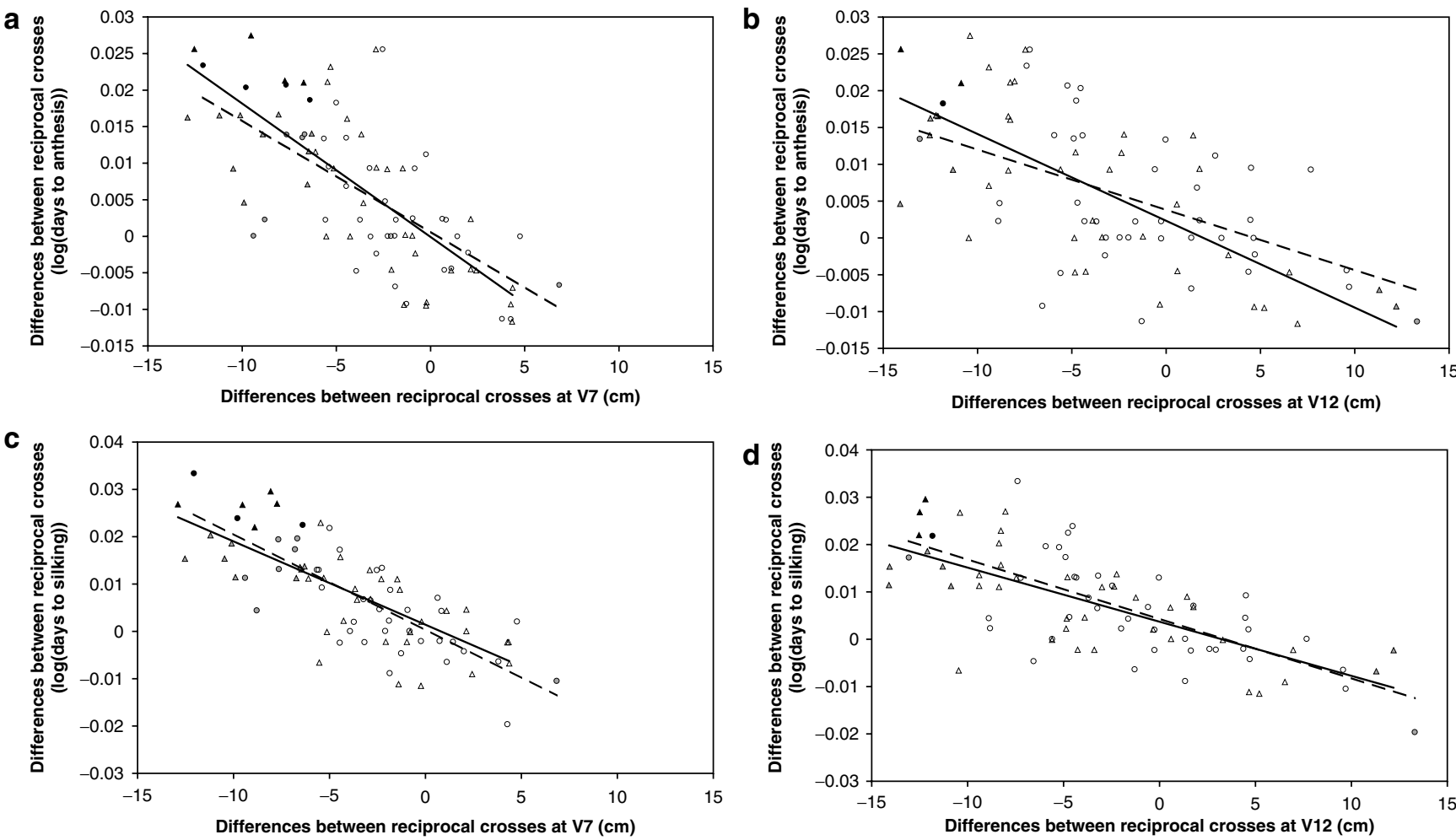

Figure 3 The relationship between differences between reciprocal crosses for days to anthesis and silking (log scale) and differences between reciprocals for (a and $\mathbf{c}$ ) plant height at the V7 stage and (b and d) V12 stage. Circles correspond to differences in high-density stand and triangles correspond to differences in low-density stands. Significant differences between reciprocals for both traits are in black. Differences that were significant for days to anthesis or silking, but not for plant height, are represented by empty black symbols. Differences that were not significant for days to anthesis and silking, but significant for plant height, are in gray. The solid line represents the linear fit for lowdensity observations and the dashed line represents the linear fit for high-density observations.

(Lejeune and Bernier, 1996). This uppermost ear is normally located at the 12th to 14 th stalk node, corresponding to the 12th to 14th leaf of the plant.

Since ear and tassel initiation is complete around the V5 stage (Lejeune and Bernier, 1996), then if the underlying maternal effects, cytoplasmic effects or 'parent-oforigin' effects are common between the vegetative and reproductive functions of the plant, we would expect to see a relationship between differences at the V7 stage and flowering traits (e.g. delayed development due to differences in plant vigor and evident at the V7 stage should result in delayed flowering). We find that the proportion of variation in difference in anthesis explained by differences in the V7 stage is 0.57 for low density and 0.44 for high density (Figure 3a). For silking, the results are slightly different with the proportion of variation in difference in silking between reciprocals explained by differences in reciprocals at the V7 stage is 0.57 for low density and 0.61 for high density (Figure 3c).

The V12 stage is measured some weeks after ear and tassel initiation is complete (Lejeune and Bernier, 1996) and so, we expect the relationship between reciprocal differences in the V12 stage and difference in the flowering of the plant to be lower than that with the V7 stage. As expected, the proportion of variation in differences in anthesis explained by differences in V12 is 0.52 in the low density and 0.25 in high density (Figure 3b). For differences in silking date, the proportion of variation explained by differences in the V12 stage is 0.53 in low density and 0.46 in high density (Figure 3d).

There is no relationship between reciprocal differences in anthesis and final height in low- and high-density stands ( $R^{2} 0.03$ and 0.09 , respectively), or between differences in silking and final height in low- and highdensity stands ( $R^{2} 0.04$ and 0.08 , respectively). However, there are only four differences between reciprocals observed at final height. Three of these four are consistently smaller across the growing season, and have shorter final heights. The fourth is the reciprocal set RIL$105 \times$ B73/B73 $\times$ RIL-105. The RIL-105 $\times$ B73 progeny were almost $10 \mathrm{~cm}$ shorter than the $\mathrm{B} 73 \times$ RIL-105 at V7, but they were almost $10 \mathrm{~cm}$ taller for final height (Table 3). Since the cytoplasm in this reciprocal is the same, these effects can not be due to cytoplasmic effects, they are unlikely due to maternal effects, and so provide evidence for 'parent-of-origin' effects.

According to the model we employed, differences in reciprocals are due to maternal effects, cytoplasmic effects and 'parent-of-origin' effects. We have shown evidence for maternal effects, and we have shown that these effects can not explain all of the reciprocal differences. We can not make conclusive statements about the existence of cytoplasmic effects, but we do not see strong evidence that these effects are large compared to the maternal effects and certainly for the cross RIL-105 $\times$ B73/B73 $\times$ RIL-105, there are no cytoplasmic effects. In addition, RIL-193 $\times$ Mo17 and RIL-105 $\times$ B73 
Table 3 Differences between reciprocals for a subset of backcrosses in which 'parent-of-origin' effects in the sporophyte are clear

\begin{tabular}{|c|c|c|c|c|c|c|c|c|c|c|c|}
\hline \multirow[t]{2}{*}{ RIL } & \multirow{2}{*}{$\begin{array}{l}\text { Backcross } \\
\text { parent }\end{array}$} & \multicolumn{5}{|c|}{ Low density } & \multicolumn{5}{|c|}{ High density } \\
\hline & & $\begin{array}{l}\text { V7 height } \\
(\mathrm{cm})\end{array}$ & $\begin{array}{l}\text { V12 height } \\
\quad(\mathrm{cm})\end{array}$ & $\begin{array}{l}\text { Final height } \\
\qquad(\mathrm{cm})\end{array}$ & $\begin{array}{c}\text { Days to } \\
\text { anthesis } \\
\text { (days) }\end{array}$ & $\begin{array}{l}\text { Days to } \\
\text { silking } \\
\text { (days) }\end{array}$ & $\begin{array}{l}\text { V7 height } \\
(\mathrm{cm})\end{array}$ & $\begin{array}{l}\text { V12 height } \\
(\mathrm{cm})\end{array}$ & $\begin{array}{l}\text { Final height } \\
\quad(\mathrm{cm})\end{array}$ & $\begin{array}{c}\text { Days to } \\
\text { anthesis } \\
\text { (days) }\end{array}$ & $\begin{array}{c}\text { Days to } \\
\text { silking } \\
\text { (days) }\end{array}$ \\
\hline 5 & B73 & -2.90 & -7.47 & -1.83 & 1.81 & $0.91^{\mathrm{a}}$ & -2.53 & -7.23 & 3.13 & 1.81 & 0.91 \\
\hline 105 & B73 & -5.30 & -9.40 & 1.47 & 1.64 & 0.79 & -9.80 & -4.53 & 9.63 & 1.44 & 1.69 \\
\hline 193 & Mol7 & -5.46 & -8.27 & -4.73 & 1.49 & 1.62 & -6.40 & -4.77 & -2.13 & 1.32 & 1.59 \\
\hline
\end{tabular}

Time to flowering is expressed in days. Differences are presented as the difference between RIL $\times$ parent and parent $\times$ RIL values. Differences that were significant using a false discovery rate of $5 \%$ are in boldface.

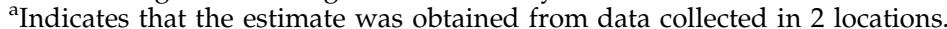

flowered about 1.5 days later than their reciprocal crosses in low density, without a corresponding difference in height early in the season. RIL-5 $\times$ B73 did not differ from its reciprocal cross for any of the heights evaluated in the study, but RIL- $5 \times$ B73 reached anthesis almost 2 days later than the reciprocal B73 $\times$ RIL-5 in both densities (Table 3). This leads us to conclude that 'parentof-origin' effects must have some effect on these phenotypic differences.

\section{Mapping the reciprocal effect}

Using equation 17 in the appendix, we mapped the effects of the reciprocals for all the traits measured in this study. Results for height at the V12 stage, final height, and days to silking are shown in Table 4 .

For each trait, we examined whether the expected $v_{a}^{m}$ and $v_{b}^{m}$ (equations 15 and 16 in Appendix A) were indeed equal and of opposite sign before pooling, and we found no evidence for departure from this assumption so all results reported are based on the pooled estimate $v^{m}$ (equation 17).

If the differences between reciprocal crosses for a trait are observed in the sporophyte exclusively due to differences in kernel quality, the same markers would be expected to be associated with the differences between reciprocal crosses for kernel weight and the trait. Although the precision of this analysis is limited due to the number of lines included, the comparison of the marker effects $v^{m}$ for kernel weight, which can be assumed to have little contribution from the embryo nuclear DNA, to the $v_{j}^{m}$ for the differences between reciprocal crosses for other traits allow us to detect large regions associated with effects on reciprocal differences that do not result from 'maternal effects'. Figures 4 and 5 compare the $v_{j}^{m}$ from all five traits evaluated in this study with the $v^{m}$ from kernel weight for chromosomes 2 and 7, respectively.

As expected from the strong relationship between the differences between reciprocal crosses in kernel weight and height to the V7 stage (Figure 2a), $v^{m}$ for kernel weight and plant height at the V7 stage were almost identical (Figures 4 and 5) in both density treatments. For example, all four markers significant for V7 height on chromosome 2 and 7 were also significant for kernel weight. This indicates that the differences between reciprocal crosses observed for V7 height are most likely due to differences in kernel quality that affected seedling vigor and early plant growth.

The influence of differences in kernel weight on the differences between reciprocal for V12 height was less evident. The estimates $v^{m}$ for V12 height tended to be smaller (in absolute value) than $v^{m}$ for kernel weight (Figures 4 and 5). As expected from the significant density by reciprocal difference interaction (Tables 1 and 3 ), the profile for V12 height in high density departed from the profile for kernel weight more than the profile in low density (Figures 4 and 5). While in the low-density stand most of the differences between reciprocal crosses were more likely due to attenuated effects of kernel weight, differences between crosses in the high density could not be attributed to effects of kernel weight.

The effect of kernel weight on the differences between reciprocals disappeared almost completely for final height (Figure 2c). Consequently, markers that were associated with differences between reciprocals in kernel weight, and therefore, plant height at the V7 stage, often showed different effects for differences in final height at both densities (Figures 4 and 5). For example, $v^{m}$ for marker bnl7.49c on chromosome 2 was negative and significant for kernel weight, but positive for final height at low density (Figure 4). In addition, the only marker (umc16a on chromosome 3) that was significant $(P=0.0075)$ for differences between reciprocal crosses for final height was not significant $(P=0.5805)$ for kernel weight.

These examples suggest that there are other factors besides maternal effects involved in determining the differences between reciprocal crosses. Further evidence for this was found in the analysis of the contribution of each marker to the difference between reciprocal crosses for days to anthesis and silking. In addition to some of the markers significantly associated with kernel weight, other markers were significant for differences between reciprocal crosses in days to anthesis and silking. For example, markers bnlg381 on chromosome 2 and phi069 on chromosome 7 were significant for days to anthesis and silking in low-density stands (Figures 4 and 5). On chromosome 2, markers bnl12.09 and bngl371 were significant for differences between reciprocal crosses in days to anthesis in high density (Figure 4). Marker phi015 on chromosome 8 was significantly associated with differences between reciprocal crosses for days to silking in low-density stands.

To directly test whether the significance of markers for anthesis and silking was due to linkage to a marker significant for kernel weight, we used the ANOVA model (2) and included the differences in kernel weight between reciprocals as a covariate in this model. If $v_{j}^{m}$ were significant after adjusting for differences in kernel weight, there is evidence that the contribution 
Table 4 Reciprocal effects $v^{m}$ for the markers that were significantly $(P<0.01)$ associated with reciprocal differences for height at the V7 and V12 stages, final height, and days to anthesis and silking

\begin{tabular}{|c|c|c|c|c|c|c|c|c|}
\hline \multirow[t]{2}{*}{ Chromosome } & \multirow[t]{2}{*}{ Marker } & \multirow[t]{2}{*}{ Position (cM) } & \multirow[t]{2}{*}{ Density } & \multicolumn{5}{|c|}{ Trait } \\
\hline & & & & $V 7$ height $(\mathrm{cm})$ & VI2 height $(\mathrm{cm})$ & Final height $(\mathrm{cm})$ & Days to anthesis & Days to silking \\
\hline \multirow[t]{3}{*}{1} & Bnl5.62a & 10.1 & Low & & & & & -0.59 \\
\hline & & & High & & & & & -0.68 \\
\hline & Bnl7.08b & 141.7 & $\begin{array}{l}\text { Low } \\
\text { High }\end{array}$ & & 5.09 & & & \\
\hline \multirow[t]{13}{*}{2} & Bnl7.49c & 25.7 & Low & -4.08 & & & 0.77 & 0.90 \\
\hline & & & High & -3.66 & & & 0.68 & 0.61 \\
\hline & Umc6 & 41.1 & Low & -4.29 & & & 0.77 & 0.93 \\
\hline & & & High & & & & & \\
\hline & Umc44b & 50.2 & Low & & -5.62 & & & \\
\hline & & & High & & & & & \\
\hline & Bngl381 & 71.9 & $\begin{array}{l}\text { Low } \\
\text { High }\end{array}$ & & -5.25 & & 0.68 & 0.72 \\
\hline & Bnl12.09 & 79.1 & Low & & & & & \\
\hline & & & High & & & & 0.65 & \\
\hline & Bngl371 & 100.5 & Low & & & & & \\
\hline & & & High & & & & 0.65 & \\
\hline & Bngl180 & 101.8 & Low & & & & & \\
\hline & & & High & & & & 0.65 & \\
\hline \multirow[t]{4}{*}{3} & Umc16a & 133 & Low & & & & & \\
\hline & & & High & & & -3.93 & & \\
\hline & Umc63 & 151.1 & Low & & & & & \\
\hline & & & High & & -5.90 & & & 0.72 \\
\hline \multirow[t]{3}{*}{5} & Nc130 & 0 & Low & & & & -0.66 & \\
\hline & Nc007 & 22.4 & $\begin{array}{l}\text { High } \\
\text { Low }\end{array}$ & & & & -063 & \\
\hline & NeUO/ & 22.4 & $\begin{array}{l}\text { Low } \\
\text { High }\end{array}$ & & & & -0.63 & \\
\hline \multirow[t]{5}{*}{7} & Asg034 & 20.6 & Low & -4.48 & & & 0.64 & \\
\hline & & & High & -3.43 & & & & \\
\hline & Bngl155 & 63.9 & $\begin{array}{l}\text { Low } \\
\text { High }\end{array}$ & -3.89 & & & 0.74 & 0.67 \\
\hline & Phi069 & 69.1 & Low & & & & 0.78 & 0.77 \\
\hline & & & High & & & & & \\
\hline \multirow[t]{9}{*}{8} & Npi220 & 0 & Low & -3.84 & & & 0.73 & 0.80 \\
\hline & & & High & & & & & \\
\hline & Bn19.11 & 44.2 & Low & -5.47 & & & 0.68 & 0.77 \\
\hline & & & High & -3.44 & & & & \\
\hline & Umc92b & 57 & $\begin{array}{l}\text { Low } \\
\text { Hioh }\end{array}$ & -4.27 & & & & \\
\hline & Phil19 & 57.3 & Low & -4.70 & -5.55 & & & \\
\hline & & & High & & & & & \\
\hline & Phi015 & 173.4 & Low & & & & & -0.70 \\
\hline & & & High & & & & & \\
\hline \multirow{3}{*}{9} & Nc134 (gl15) & 66.5 & $\begin{array}{l}\text { Low } \\
\text { High }\end{array}$ & & 5.44 & & & \\
\hline & Bnl14.28 & 125.6 & Low & 3.91 & & & & \\
\hline & & & High & 3.83 & & & -0.66 & -0.68 \\
\hline
\end{tabular}

Marker positions correspond to those presented by Senior et al. (1996).

of $\left(s n_{B, B M}^{m}-s n_{M, B M}^{m}\right)+\left(p n_{M, B M}^{m}-p n_{B, B M}^{m}\right)$ to $v_{j}^{m}$ in equation 15 and 16 is statistically different from 0 . All $v_{j}^{m}$ remained significant after including differences in kernel weight as a covariate.

\section{Conclusions}

We developed an approach for mapping reciprocal differences. Mapping allows us to determine whether the reciprocal differences observed in different traits, and at different densities, colocalize to common regions of the genome. For each trait, we tested marker-trait association using a pooled estimate that accounts for the difference in cytoplasmic DNA (equations 15 and 16), after verifying that effect in both backcrosses was similar.
We were able to map all of the reciprocal traits and we found significant markers associated with all traits (see Figures 4 and 5).

Our study provides evidence for the impact of maternal effects on phenotypes such as kernel weight, V7, V12 stages anthesis and silking. Furthermore, the maternal effect is influenced by density. While kernel weight is associated with height at the V7 and V12 stages, days to anthesis, and days to silking it does not explain the majority of the variation in these traits, leading to the conclusion that factors other than maternal effects must also be at play. If maternal effects were the only determinant of the differences between reciprocals crosses, phenotypes measured later in development should exhibit the same pattern as those observed for 

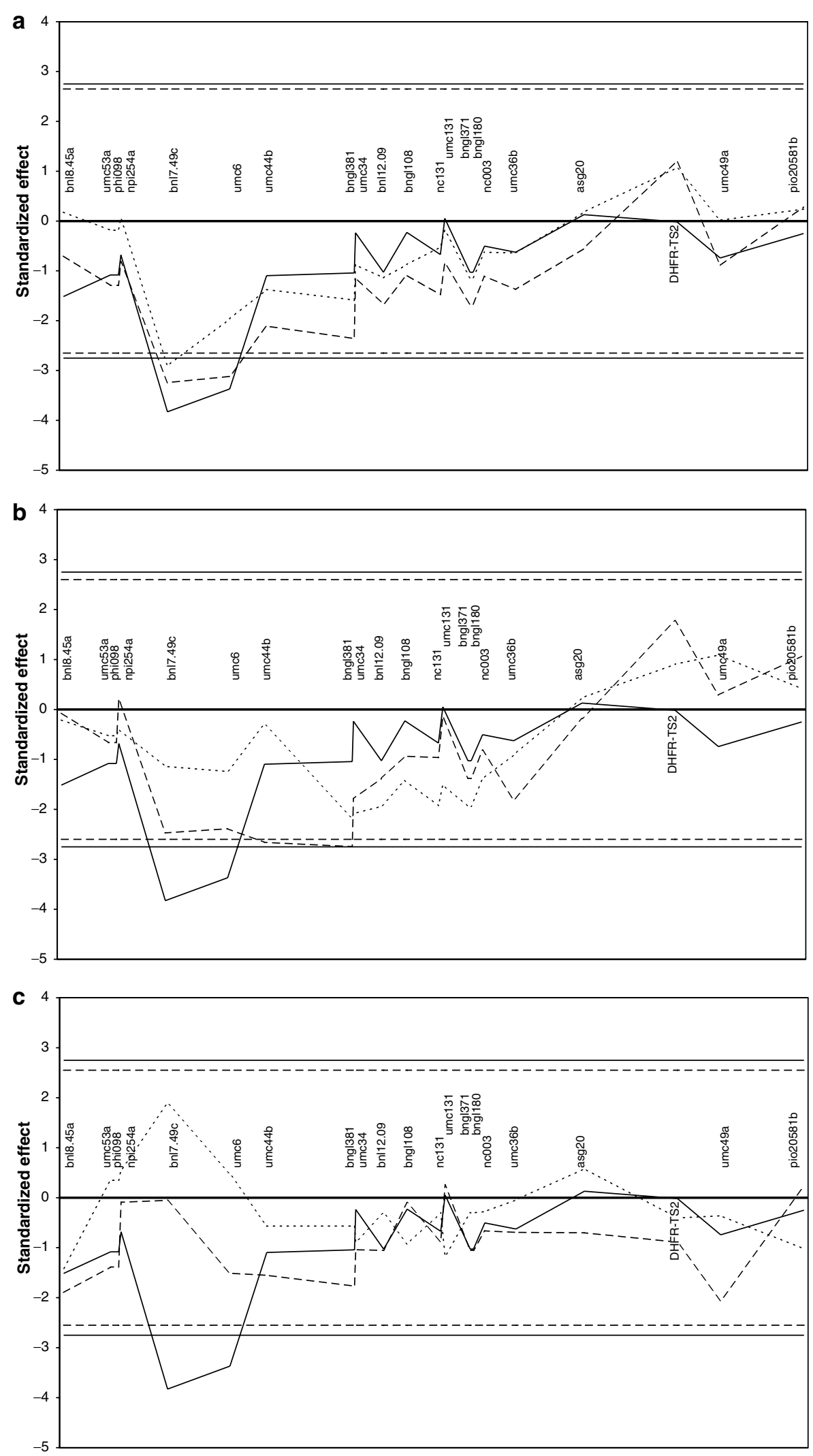

Figure 4 Estimated $v_{j}^{m}$ for markers on chromosome 2 for (a) height at the V7 stage, (b) height at the V12 stage, (c) final height, (d) days to anthesis (log scale) and (e) days to silking (log scale). Standardized $v_{j}^{m}$ were computed as $v_{j}^{m}$ divided by its s.e. Negative values of the standardized effects for days to anthesis and silking were multiplied by -1 so that late flowering corresponds to smaller kernels. Dashed horizontal lines represent the threshold for traits measured on the sporophyte at a 0.01 significance level. Solid horizontal lines represent the threshold for kernel weight at a 0.01 significance level. Solid, dashed, and dotted profiles represent the standardized $v_{j}^{m}$ for kernel weight, traits measured on the sporophyte in high- and low density, respectively. 

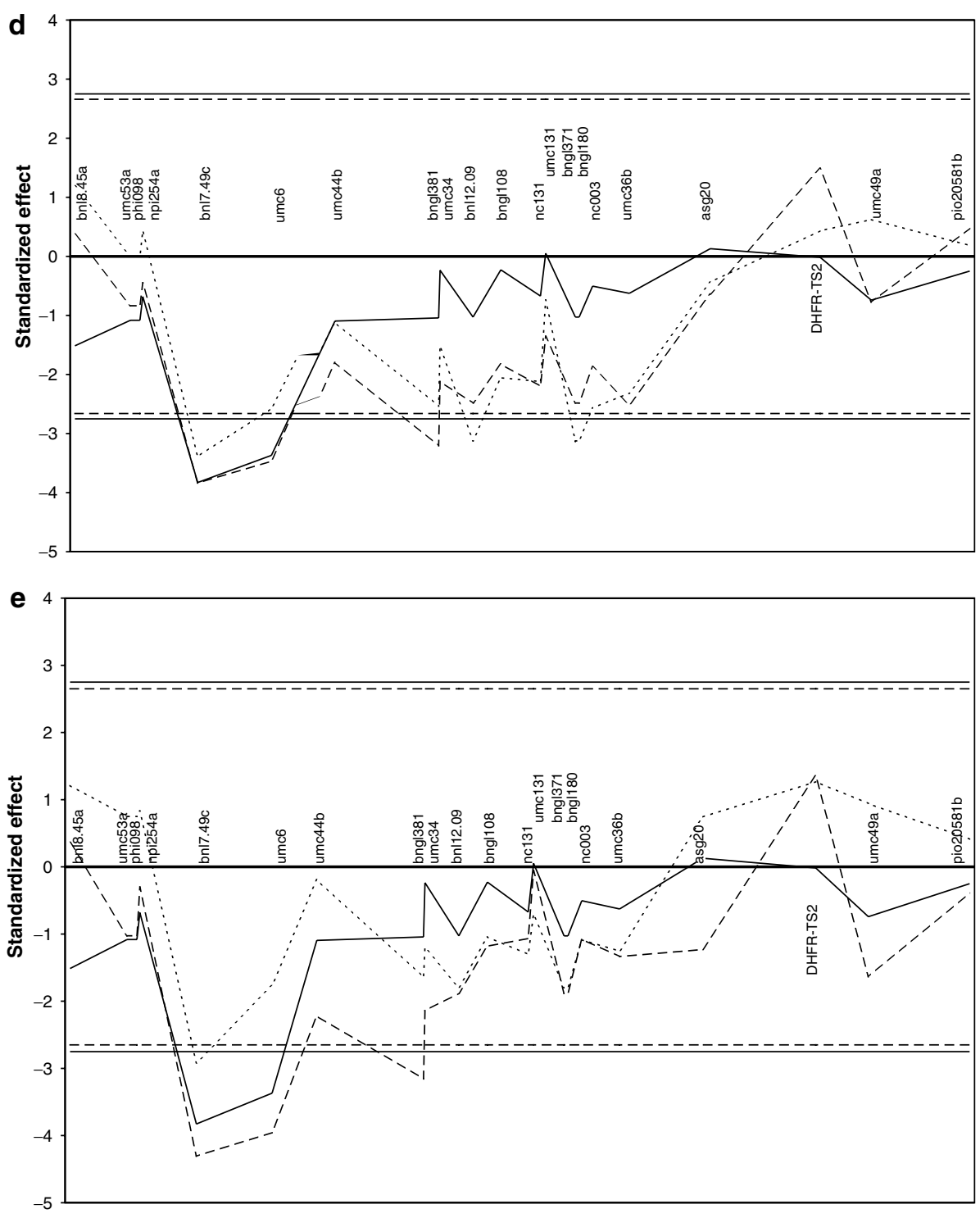

Figure 4 Continued.

the kernel weight. This is not always the case, and there are specific counter examples that are inconsistent with this hypothesis (Table 3). The majority of these counter examples occur in reciprocal crosses in the B73 background. As the RIL has the same cytoplasm as the B73 parent, in these cases, there is no cytoplasmic effect. This leads us to conclude that there is evidence for 'parentof-origin' effects for at least some of the reciprocal differences we observed.

Growth of the maize endosperm and early embryo development are tightly regulated by maternal zygotic and sporophytic genes, some of which are imprinted (Lin, 1982; Lund et al., 1995a, b; Chaudhury and Berger, 2001; Evans and Kermicle, 2001; Danilevskaya et al., 2003; Gutierrez-Marcos et al., 2004; Lauria et al., 2004; Grimanelli et al., 2005). From seedling onwards, maize plants are able to detect neighbors through red/far-red signals (Kasperbauer and Karlen, 1994; Maddonni et al., 2002). Higher plant population densities triggers neighbordetecting mechanisms and responses at earlier develop- mental stages than lower population densities (Maddonni and Otegui, 2004). Therefore, differences between reciprocal crosses exclusively due to differences in kernel characteristics would be expected to dilute earlier at high than at low density, and, eventually, they would disappear at both densities. This pattern is completely consistent with our data. A phenomenon that may contribute to differences between reciprocals in our study is imprinting. Imprinting has been described for endosperm and early embryo development in plants (Alleman and Doctor, 2000; Autran et al., 2005) and recently in adult sporophytic tissue (Kollipara et al., 2002; Lauria et al., 2004).

The regions with significant $v_{j}^{m}$ for days to anthesis and silking that were independent from differences in kernel weight can also be compared by map position to loci previously identified in $\mathrm{B} 73 \times$ Mo17 mapping populations. bnlg180 is closely linked (approximately $3 \mathrm{cM}$ on Pioneer 1999 Composite Map, www.maizegdb.org) to a major QTL for heat units to pollen shed in the 

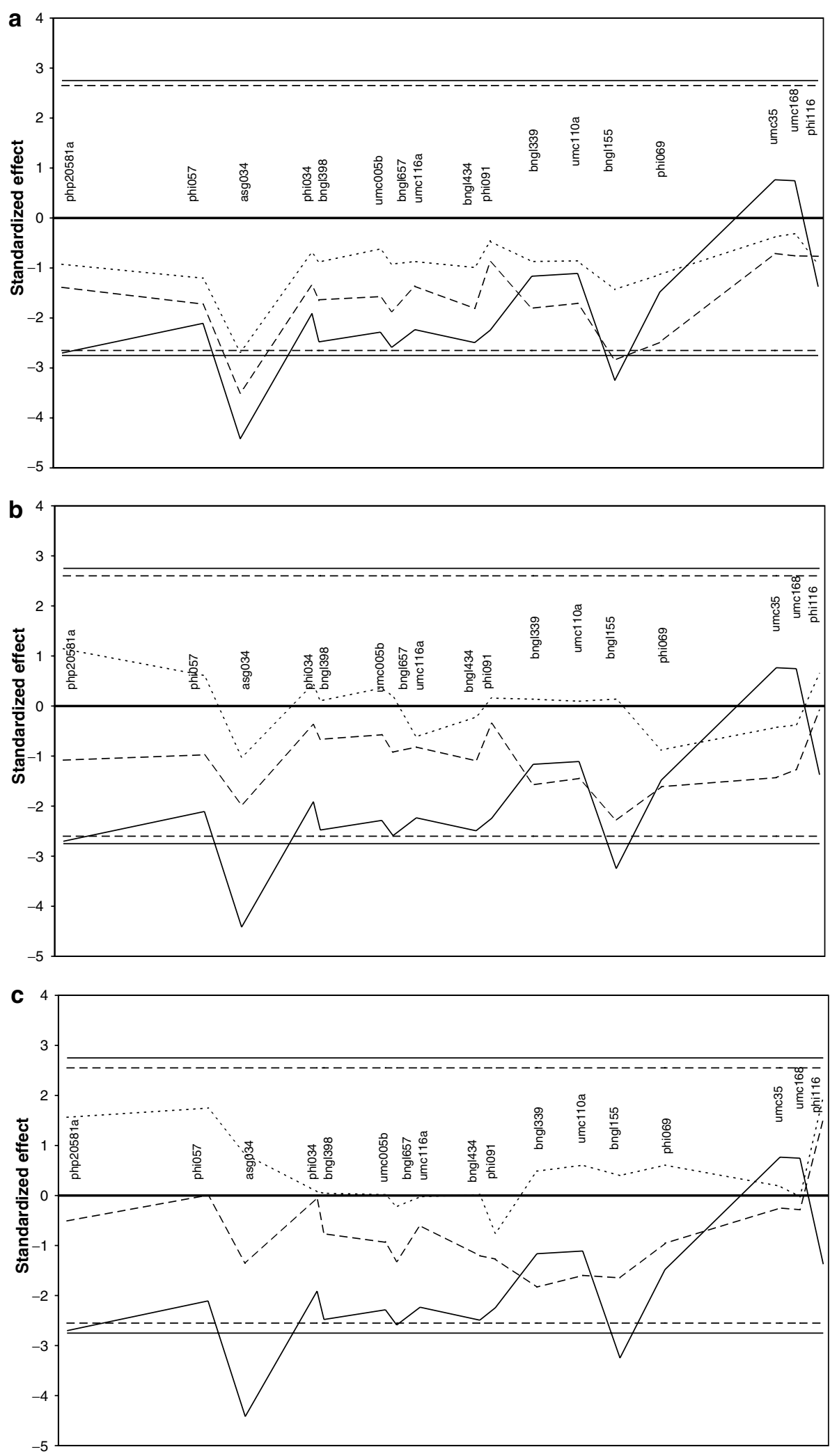

Figure 5 Estimated $v_{j}^{m}$ for markers on chromosome 7 for (a) height at the V7 stage, (b) height at the V12 stage, (c) final height, (d) days to anthesis (log scale) and (e) days to silking (log scale). Standardized $v_{j}^{m}$ were computed as $v_{j}^{m}$ divided by its s.e. Negative values of the standardized effects for days to anthesis and silking were multiplied by -1 so that late flowering corresponds to smaller kernels. Dashed horizontal lines represent the threshold for traits measured on the sporophyte at a 0.01 significance level. Solid horizontal lines represent the threshold for kernel weight at a 0.01 ignificance level. Solid, dashed and dotted profiles represent the standardized $v_{j}^{m}$ for kernel weight, traits measured on the sporophyte in high- and low density, respectively. 

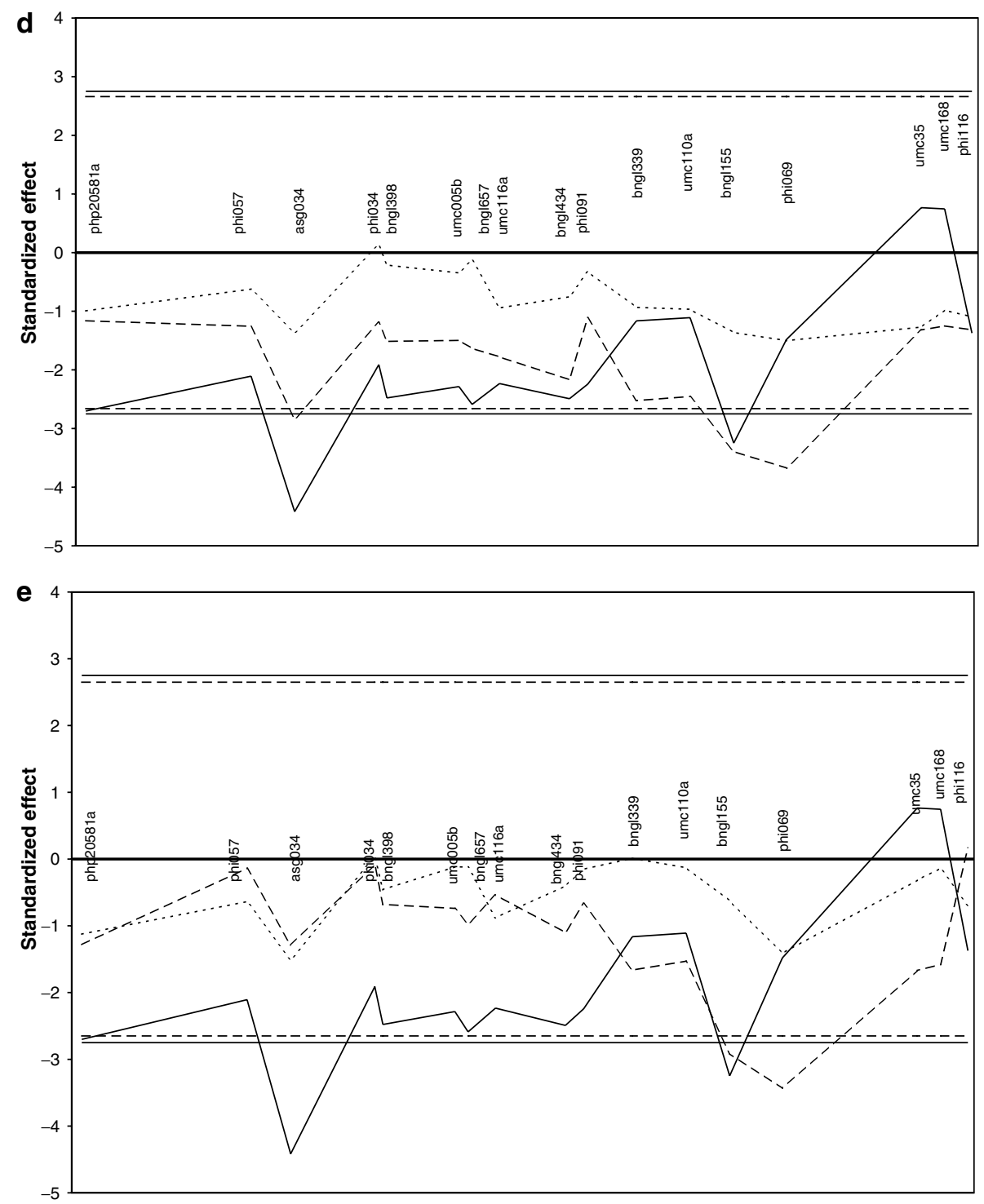

Figure 5 Continued.

B73 $\times$ Mo17 F2 population studied by Beavis et al. (1994). Perhaps more interesting is the fact that phi069 on chromosome 7 is closely linked (approximately $5 \mathrm{cM}$ on Pioneer 1999 Composite Map, www.maizegdb.org) to alpha tubulin 6, a gene that pertains to a family that is differentially demethylated in the endosperm relative to the embryo and seedling (Lund et al., 1995a, b).

In our case, we can explicitly exclude the effect of the cytoplasm in some crosses. Unfortunately, little additional information is available about the extension of imprinting phenomena in sporophytic tissues in maize and so it is impossible to determine whether this mechanism was definitively involved in the reciprocal differences we observed. However, our results are consistent with this mechanism and suggest that this would be an interesting avenue for further study.

\section{Acknowledgements}

This work is supported by the Purdue University agricultural research center, USDA-NRI-CGP Award
No. 2001-35301-10601 (JBH) and NIH 1R24GM65513-01 (LMM). William Foster and Phil Devillez were critical in the planting, harvesting and execution of this experiment. Sergio Kimoto and Matias Canepa helped score phenotypes in the field and the University of Florida population genomics discussion group provided valuable feedback on the manuscript.

\section{References}

Aksel R (1977). Quantitative genetically nonequivalent reciprocal crosses in cultivated plants. In: Muhammed A, Aksel R, von Borstel R (eds). Genetic Diversity in Plants. Plenum: New York, NY, pp. 269-280.

Alleman M, Doctor J (2000). Genomic imprinting in plants: observations and evolutionary implications. Plant Mol Biol 43: 147-161.

Autran D, Huanca-Mamani W, Vielle-Calzada J (2005). Genomic imprinting in plants: the epigenetic version of an Oedipus complex. Curr Opin Plant Biol 8: 19-25. 
Bagnara D, Daynard T (1983). Reciprocal differences in kernel growth among four maize inbreds. Maydica 27: 357-363.

Bdliya P, Burris J (1988). Diallel analysis of tolerance of drying injury in seed corn. Crop Sci 28: 935-938.

Beavis W, Smith O, Grant D, Fincher R (1994). Identification of quantitative trait loci using small sample of topcrossed and F4 progeny from maize. Crop Sci 34: 882-896.

Benjamini Y, Hochberg Y (1995). Controlling the false discovery rate -a practical and powerful approach to multiple testing. J Royal Stat Soc Ser B-Met 57: 289-300.

Birchler J, Hart J (1987). Interaction of endosperm size factors in maize. Genetics 117: 309-317.

Cal JP, Obendorf R (1972). Imbibitional chilling injury in Zea mays L. altered by kernel moisture and maternal parent. Crop Sci 12: 369-373.

Cervera M, Ruiz-Garcia L, Martinez-Zapater J (2002). Analysis of DNA methylation in Arabidopsis thaliana based on methylation-sensitive AFLP markers. Mol Genet Genomics 268: 543-552.

Chaudhuri S, Messing J (1994). Allele-specific parental imprinting of dzr1, a posttranscriptional regulator of zein accumulation. Proc Natl Acad Sci USA 91: 4867-4871.

Chaudhury A, Berger F (2001). Maternal control of seed development. Semin Cell Dev Biol 12: 381-386.

Danilevskaya O, Hermon P, Hantke S, Muszynski M, Kollipara K, Ananiev E (2003). Duplicated fie genes in maize: expression pattern and imprinting suggest distinct functions. Plant Cell 15: 425-438.

Dhliwayo T, Pixley K, Kazembe V (2005). Combining ability for resistance to maize weevil among 14 Southern African maize inbred lines. Crop Sci 45: 662-667.

Eagles H, Hardacre A (1979). Genetic variation in maize Zea mays for germination and emergence at 10 celcius. Euphytica 28: 287-296.

Evans M, Kermicle J (2001). Interaction between maternal effect and zygotic effect mutations during maize seed development. Genetics 159: 303-315.

Finnegan E (2001). Epialleles - a source of random variation in times of stress. Curr Opin Plant Biol 5: 101-106.

Grimanelli D, Perotti E, Ramirez J, Leblanc O (2005). Timing of the maternal-to-zygotic transition during early seed development in maize. Plant Cell 17: 1061-1072.

Gutierrez-Marcos J, Costa L, Biderre-Petit C, Khbaya B, O'Sullivan D, Wormald M et al. (2004). Maternally expressed gene1 is a novel maize endosperm transfer cell-specific gene with a maternal parent-of-origin pattern of expression. Plant Cell 16: 1288-1301.

Kakutani T, Jeddeloh J, Flowers S, Munakata K, Richards E (1996). Developmental abnormalities and epimutations associated with DNA hypomethylation mutations. Proc Natl Acad Sci USA 93: 12406-12411.

Kasperbauer M, Karlen D (1994). Plant spacing and reflected far-red light effects on phytochrome-regulated photosynthate allocation in corn seedlings. Crop Sci 77: 393-398.

Kermicle J (1970). Dependence of the r-mottled aleurone phenotype in maize on mode of sexual transmission. Genetics 66: 69-85.

Kollipara K, Saab I, Wych R, Lauer M, Singletary G (2002). Expression profiling of reciprocal maize hybrids divergent for cold germination and desiccation tolerance. Plant Physiol 129: 974-992.

Lauria M, Rupe M, Guo M, Kranz E, Pirona R, Viotti A et al. (2004). Extensive maternal DNA hypomethylation in the endosperm of Zea mays. Plant Cell 16: 510-522.

Lawless J (1982). Statistical Models and Methods for Lifetime Data. Wiley: New York.

Lejeune P, Bernier G (1996). Effect of environment on the early steps of ear initiation in maize Zea mays L. Plant Cell Environ 19: $217-224$.

Lin B-Y (1982). Association of endosperm reduction with parental imprinting in maize. Genetics 100: 475-486.
Lund G, Ciceri P, Viotti A (1995a). Maternal-specific demethylation and expression of specific alleles of zein genes in the endosperm of Zea mays L. Plant Journal 8: 571-581.

Lund G, Messing J, Viotti A (1995b). Endosperm-specific demethylation and activation of specific alleles of alphatubulin genes of Zea mays L. Mol Gen Genet 246: 716-722.

Maddonni G, Otegui M (2004). Intra-specific competition in maize: early establishment of hierarchies among plants affects final kernel set. Field Crops Res 85: 1-13.

Maddonni G, Otegui M, Andrieu B, Chelle M, Casal J (2002). Maize leaves turn away from neighbors. Plant Physiol 130: 1181-1189.

Mann C, Pollmer W (1981). Reciprocal-cross differences between maize hybrids of inbred lines from different gene pools. Maydica 26: 263-271.

Mann C, Pollmer W, Klein D (1981). Magnitude and stability over environments of reciprocal-cross differences in maize hybrids and their implications on mayze breeding. Maydica 26: 239-252.

Martienssen R, Colot V (2001). DNA methylation and epigenetic inheritance in plants and filamentous fungi. Science 293 : 1070-1074

Melchinger A, Geiger H, Schnell F (1985). Reciprocal differences in single-cross hybrids and their F2 and backcross progenies in maize. Maydica 30: 395-405.

Pollmer W, Klein D, Dhillon B (1979). Differences in reciprocal crosses of maize inbred lines diverse for protein content. Euphytica 28: 325-328.

Reik W, Walter J (2001). Uenomic imprinting: parental influence on the genome. Nature Rev Genet 2: 21-32.

Ritchie S, Hanway J, Benson G (1992). How a corn plant develops. Iowa State Univ. Sp. Rpt. No. 48. Available online at http://maize.agron.iastate.edu/corngrows.html (viewed March 15, 2006).

Roach DA, Wulff RD (1987). Maternal effects in plants. Ann Rev Ecol Syst 18: 209-235.

Rutherford S, Henikoff S (2003). Quantitative epigenetics. Nature Genet 33: 6-8.

Schnell F, Singh I (1978). Epistasis in three-way crosses involving early flint and dent lines of maize. Maydica 23: 233-238.

Seitz G, Melchiger A, Geiger H, Singh I (1995). Reciprocal differences for forage traits in single and three-way crosses of maize. Plant Breeding 114: 231-234.

Senior L, Chin E, Lee M, Smith JSC, Stuber C (1996). Simple sequence repeat markers developed from maize sequences found in the GENBANK database: map construction. Crop Science 36: 1676-1683.

Sherman J, Talbert L (2002). Vernalization-induced changes of the DNA methylation pattern in winter wheat. Genome 45: 252-260.

Steward N, Ito M, Yamachuchi Y, Koizumi N, Sano H (2002). Periodic DNA methylation in maize nucleosomes and demethylation by environmental stress. J Biol Biochem 277: 37741-37746.

Tani E, Polidoros A, Nianiou-Obeidat I, Tsaftaris A (2005). DNA methylation patterns are differently affected by planting density in maize inbreds and their hybrids. Maydica 50: 19-23.

Tsaftaris A, Kafka A, Polidoros A, Tani E (1999). Epigenetic changes in maize DNA and heterosis. In: Coors J (ed). The Genetics and Exploitation of Heterosis in Crops. Am. Soc. Agronomy: Madison, WI. pp 195-203.

Tsaftaris A, Polidoros A (2000). DNA methylation and plant breeding. Plant Breed Rev 18: 87-176.

Verhoeven K, Simonsen K, McIntyre L (2005). Implementing false discovery rate control: increasing your power. Oikos 108: 643-647.

Vermerris W, McIntyre L (1999). Time to flowering in brown midrib mutants of maize: an alternative approach to the analysis of developmental traits. Heredity 83: 171-178. 


\section{Appendix A}

For a given trait, $Y_{i j k l}$, the genetic value for any genotype in our study can be modeled as:

$$
\begin{aligned}
Y_{i j k l}= & S_{i}+P_{j}+N_{k}+C_{i}+S P_{i j}+S C_{i}+P C_{j i}+S N_{i k} \\
& +P N_{j k},
\end{aligned}
$$

where $Y_{i j k l}$ represents the genetic value for the cross involving the $l$ th RIL $(l=1 \ldots 23)$, with genotype $i$ as the seed parent, $i=\{\mathrm{B} 73(\mathrm{~B}), \operatorname{Mo} 17(\mathrm{M}), \mathrm{RIL}(\mathrm{R})\}$, genotype $j$ as the pollen parent, $j=\{\mathrm{B} 73(\mathrm{~B}), \operatorname{Mo17}(\mathrm{M}), \mathrm{RIL}(\mathrm{R})\}$, nuclear DNA $k, k=\{\mathrm{B} 73 \times \mathrm{RIL}(\mathrm{B} \times \mathrm{R}), \quad \mathrm{Mo} 17 \times \mathrm{RIL}$ $(\mathrm{M} \times \mathrm{R})\} . S_{i}$, the effect of having genotype $i$ as the seed parent, represents the effect of the seed parent $i$ on its progeny kernels and includes the contribution of this parent to the genotype of the endosperm of the resulting backcross progeny. $P_{j}$, the effect of having genotype $j$ as the pollen parent, corresponds to the contribution of the pollen parent to the genotype of the resulting backcross progeny. The effects $S_{i}$ and $P_{j}$ identify genetic effects that directly impact kernel characteristics. $N_{k}$ is the effect of the nuclear DNA of the progeny (DNA in the nucleus). $C_{i}$ is the effect of extranuclear DNA, or the cytoplasmic DNA inherited from the seed parent $i$. Since the RIL lines were developed by backcrossing to B73, with B73 as the seed parent, all RIL lines have the same cytoplasmic components as the B73 inbred line. This is distinct from the effect of the seed parent on the endosperm $S_{i}$.

The interaction between the contributions of the seed parent/pollen parent, the interactions between the seed parent and cytoplasmic DNA, and the interactions between the pollen parent and cytoplasmic DNA can only be estimated via complex manipulations. The interaction between the seed parent and the pollen parent can only be estimated if all combinations of seed and pollen parent are observed. In our design, we do not have such combinations and so this interaction is confounded with the main effects of the seed and pollen parent. $S N_{i k}$ represents the interaction between the effect of the nuclear DNA $k$ and seed parent $i$. Similarly, $P N_{j k}$ represents the interaction between the effect of the nuclear DNA $k$ and pollen parent $j$. Taking these factors into consideration, equation (3) reduces to:

$$
Y_{i j k l}=S_{i}+P_{j}+N_{k}+C_{i}+S N_{i k}+P N_{j k}
$$

We refer to the $S_{i}$ component as the effect of the seed parent, the $P_{j}$ component as the effect of the pollen parent, the $C_{i}$ component as the 'cytoplasmic effect'. In all but a few cases (Lin, 1982; Birchler and Hart, 1987), kernel size and kernel characteristics are largely determined by the seed parent. Since the objective of this study is not to separate the effects of the seed parent from the effects of the pollen parent, but to separate 'parent-of-origin' effects in the sporophyte from other sources, we refer to $S_{i}+P_{j}$ collectively as the 'maternal effect' (Figure 1). For simplicity, we omit the three-and four-way interaction terms from this model.

For the backcrosses $\mathrm{B} 73 \times \mathrm{RIL}_{l}, \mathrm{RIL}_{l} \times \mathrm{B} 73, \mathrm{Mo} 17 \times \mathrm{RIL}_{l}$, and $\mathrm{RIL}_{l} \times \mathrm{Mo}_{17}$, for $\mathrm{RIL}_{l}$, equation (4) can be written as:

$$
\begin{aligned}
Y_{B, R_{l}, B x R_{l}} & =S_{B}+P_{R_{l}}+N_{B x R_{l}}+C_{B}+S N_{B, B x R_{l}}+P N_{R_{l}, B x R_{l}}, \\
Y_{R_{l}, B, R_{l} x B} & =S_{R_{l}}+P_{B}+N_{B x R_{l}}+C_{B}+S N_{R_{l}, B x R_{l}}+P N_{B, B x R_{l}}, \\
Y_{M, R_{l}, M x R_{l}} & =S_{M}+P_{R_{l}}+N_{M x R_{l}}+C_{M}+S N_{M, M x R_{l}}+P N_{R_{l}, M x R_{l}}, \\
Y_{R_{l}, M, R_{l} x M} & =S_{R_{l}}+P_{M}+N_{M x R_{l}}+C_{B}+S N_{R, M x R_{l}}+P N_{M, M x R_{l}} .
\end{aligned}
$$

The expected difference between reciprocal crosses for RIL $l$ can be obtained by subtraction of reciprocal crosses involving B73:

$$
\begin{aligned}
Y_{R_{l}, B, R_{l} x B}- & Y_{B, R_{l}, B x R_{l}}=\left(S_{R_{l}}-S_{B}\right)+\left(P_{B}-P_{R_{l}}\right) \\
& +\left(S N_{R_{l}, B x R_{l}}-S N_{B, B x R_{l}}\right) \\
& +\left(P N_{B, B x R_{l}}-P N_{R_{l}, B x R_{l}}\right)
\end{aligned}
$$

or of reciprocal crosses involving Mol7:

$$
\begin{aligned}
Y_{R_{l}, M, R_{l} x M}- & Y_{M, R_{l}, M x R_{l}}=\left(S_{R_{l}}-S_{M}\right)+\left(P_{M}-P_{R_{l}}\right) \\
& +\left(C_{B}-C_{M}\right) \\
& +\left(S N_{R_{l}, M x R_{l}}-S N_{M, M x R_{l}}\right) \\
& +\left(P N_{M, M x R_{l}}-P N_{R_{l}, M x R_{l}}\right)
\end{aligned}
$$

For backcrosses of a single RIL to B73, notice that the sporophytic genotypes are identical, except that at polymorphic loci, the B73 alleles are derived from the pollen parent in one case and from the seed parent in the reciprocal backcross (Figure 1). In addition, at polymorphic loci these reciprocal backcrosses differ for the dosage of B73 and Mo17 alleles in the endosperm (Figure 1). Therefore, equation 5 partitions the differences between reciprocal crosses into differences in maternal effects $\left(\left(S_{R}-S_{B}\right)+\right.$ $\left.\left(P_{B}-P_{R_{l}}\right)\right)$, and 'parent-of-origin' effects $\left(\left(S N_{R_{l}, B x R_{l}}-\right.\right.$ $\left.\left.S N_{B, B x R_{l}}\right)+\left(P N_{B, B x R_{l}}-P N_{R_{l}, B x R_{l}}\right)\right)$ (Figure 1). The differences between reciprocal crosses involving Mo17 (equation 6) have an additional difference in 'cytoplasmic effects' $\left(C_{B}-C_{M}\right)$. With the exception of the cytoplasmic contribution $C_{i}$, each of the terms in equation 4 can be written in terms of individual loci. The combined effect for the $l$ th RIL is then the joint effect of all loci. Considering locus $m$, the difference between reciprocal crosses involving RIL $l$ can be written based on the marker type of the RIL and the backcross parent as follows: if RIL $l$ carries allele $a$ at locus $m$, then the difference between reciprocal crosses to backcross parent $b$ is $\left(\Lambda_{B, M, l}^{m}\right)$. For RIL $l$ with a B73 allele at marker $m$ in the backcross to Mo17

$$
\begin{aligned}
\Lambda_{B, M, l}^{m}= & \left(s_{B}^{m}-s_{M}^{m}\right)+\left(p_{M}^{m}-p_{B}^{m}\right)+\left(s n_{B, B M}^{m}-s n_{M, B M}^{m}\right) \\
& +\left(p n_{M, B M}^{m}-p n_{B, B M}^{m}\right)+\left(C_{B}-C_{M}\right)+\delta_{l},
\end{aligned}
$$

where $s_{B}^{m}$ and $s_{M}^{m}$ represent the contribution of locus $m$ to the term $S_{i} ; p_{M}^{m}$ and $p_{B}^{m}$ represent the contribution of locus $m$ to the term $P_{j} ; s n_{B, B M}^{m}$ and $s n_{M, B M}^{m}$ represent the contribution of locus $m$ to the term $S N_{i k} ; p n_{M, B M}^{m}$ and $p n_{B, B M}^{m}$ represents the contribution of locus $m$ to the term $P N_{j k} ;$ and $\delta_{l}$ represent the combined contribution of the remaining loci. If RIL $l$ carries the B73 allele at locus $m$, then the difference between reciprocal crosses to backcross parent $\mathrm{B} 73\left(\Lambda_{B, B, l}^{m}\right)$ is

$$
\Lambda_{B, B, l}^{m}=\delta_{l} \text {. }
$$

If RIL $l$ carries allele Mo17 at locus $m$, then the difference between reciprocal crosses to backcross parent Mo17 $\left(\Lambda_{M, M, l}^{m}\right)$ is

$$
\Lambda_{M, M, l}^{m}=\left(C_{B}-C_{M}\right)+\delta_{l}
$$


If RIL $l$ carries allele Mo17 at locus $m$, then the difference between reciprocal crosses to backcross parent B73 $\left(\Lambda_{M, B, l}^{m}\right)$ is

$$
\begin{aligned}
\Lambda_{M, B, l}^{m}= & \left(s_{M}^{m}-s_{B}^{m}\right)+\left(p_{B}^{m}-p_{M}^{m}\right)+\left(s n_{M, B M}^{m}-s n_{B, B M}^{m}\right) \\
& +\left(p n_{B, B M}^{m}-p n_{M, B M}\right)+\delta_{l} .
\end{aligned}
$$

For locus $m$, the 46 differences between reciprocals can be written in one of the 4 forms described above depending on the marker type of the RIL and the backcross parent. The average of the differences between reciprocal crosses involving backcross parent Mo17 for all RILs that carry allele B73 at locus $m$ is

$$
\begin{aligned}
\bar{\Lambda}_{1}^{m}= & \left(\sum_{l=1}^{n_{1}} \Lambda_{B, M, l}^{m}\right) / n_{1}=\left(s_{B}^{m}-s_{M}^{m}\right)+\left(p_{M}^{m}-p_{B}^{m}\right) \\
& +\left(s n_{B, B M}^{m}-s n_{M, B M}^{m}\right) \\
& \times\left(p n_{M, B M}^{m}-p n_{B, B M}\right)+\left(C_{B}-C_{M}\right)+\left(\sum_{l=1}^{n_{1}} \delta_{l}\right) / n_{1},
\end{aligned}
$$

where $n_{1}$ is the number of RILs in this group. Similarly, the average of the differences between reciprocal crosses involving backcross parent B73 for all RILs that carry allele B73 at locus $m$ is

$$
\bar{\Lambda}_{2}^{m}=\left(\sum_{l=1}^{n_{2}} \Lambda_{B, B, l}^{m}\right) / n_{2}+\left(\sum_{l=1}^{n_{2}} \delta_{l}\right) / n_{2} .
$$

The average of the differences between reciprocal crosses involving backcross parent Mo17 for all RILs that carry allele Mo17 at locus $m$ is

$$
\begin{aligned}
\bar{\Lambda}_{3}^{m} & =\left(\sum_{l=1}^{n_{3}} \Lambda_{M, M, l}^{m}\right) / n_{3} \\
& =\left(C_{B}-C_{M}\right)+\left(\sum_{l=1}^{n_{3}} \delta_{l}\right) / n_{3} .
\end{aligned}
$$

The average of the differences between reciprocal crosses involving backcross parent B73 for all RILs that carry allele Mo17 at locus $m$ is

$$
\begin{aligned}
\bar{\Lambda}_{4}^{m}= & \left(\sum_{l=1}^{n_{4}} \Lambda_{M, B, l}^{m}\right) / n_{4}=\left(s_{M}^{m}-s_{B}^{m}\right)+\left(p_{B}^{m}-p_{M}^{m}\right) \\
& +\left(s n_{M, B M}^{m}-s n_{B, B M}^{m}\right) \\
& \left(p n_{B, B M}^{m}-p n_{M, B M}\right)+\left(\sum_{l=1}^{n_{4}} \delta_{l}\right) / n_{4} .
\end{aligned}
$$

Subtracting the average difference between reciprocal backcrosses to B73 involving RILs homozygous B73 for the marker $m$ (equation 12) from the average difference between reciprocal backcrosses to B73 involving RILs that carry allele Mo17 for the marker $m$ (equation 14) yields an estimate of the average contribution of marker $m$ to the difference between reciprocal crosses.

$$
\begin{aligned}
v_{a}^{m}=\bar{\Lambda}_{4}^{m}-\bar{\Lambda}_{2}^{m}= & \left(s_{M}^{m}-s_{B}^{m}\right)+\left(p_{B}^{m}-p_{M}^{m}\right) \\
& +\left(s n_{M, B M}^{m}-s n_{B, B M}^{m}\right) \\
& +\left(p n_{B, B M}^{m}-p n_{M, B M}\right) .
\end{aligned}
$$

Similarly, subtraction of the average difference between reciprocal backcrosses to Mo17 involving RILs homozygous Mo17 for the marker (equation 13) from the average difference between reciprocal backcrosses to Mo17 involving RILs homozygous B73 for the marker (equation 11) is an estimate of

$$
\begin{aligned}
v_{b}^{m}=\bar{\Lambda}_{1}^{m}-\bar{\Lambda}_{3}^{m}= & \left(s_{B}^{m}-s_{M}^{m}\right)+\left(p_{M}^{m}-p_{B}^{m}\right) \\
& +\left(s n_{B, B M}^{m}-s n_{M, B M}^{m}\right) \\
& +\left(p n_{M, B M}^{m}-p n_{B, B M}\right) .
\end{aligned}
$$

Both equations 15 and 16 estimate the effect of replacing one allelic combination for the other at marker $m$. Note that the expected value of $v_{a}^{m}=-v_{b}^{m}$.

$$
v^{m}=\frac{v_{a}^{m}-v_{b}^{m}}{2}
$$

represents the average contribution of marker $m$ to the difference between reciprocal crosses. In our study, we checked that the estimates $v_{a}^{m}$ and $v_{b}^{m}$ had the opposite sign and were of the same magnitude. Then, we pooled them into a single estimate $v^{m}$ of average contribution of marker $m$ to the difference between reciprocal crosses in order to increase the statistical power for the test $v^{m}=0$. 